\title{
Consumers as Tax Auditors
}

\author{
By JOANA NARITOMI*
}

\begin{abstract}
To investigate the enforcement value of third-party information on potentially collusive taxpayers, I study an anti-tax evasion program that rewards consumers for ensuring that firms report sales and establishes a verification system to aid whistle-blowing consumers in São Paulo, Brazil (Nota Fiscal Paulista). Firms reported sales increased by at least 21 percent over 4 years. The results are consistent with fixed costs of concealing collusion, increased detection probability from whistle-blower threats, and with behavioral biases associated with lotteries amplifying the enforcement value of the program. Although firms increased reported expenses, tax revenue net of rewards increased by 9.3 percent. (JEL D22, H25, H26, L25, O14, O17)
\end{abstract}

Tax revenue as a share of GDP is substantially higher in modern advanced economies than in the early twentieth century or in present-day developing countries (Besley and Persson 2014). A key source of the variation in tax revenue is the enforcement capacity of governments..$^{1}$ In particular, a growing literature emphasizes that information on taxable transactions shared with third-parties can be leveraged by governments to ensure more accurate self-reporting, ${ }^{2}$ and that the increased availability of third-party information trails as countries develop could help explain

\footnotetext{
* Naritomi: International Development, London School of Economics, Houghton Street, London WC2A 2AE (email: J.Naritomi@1se.ac.uk). Marianne Bertrand was the coeditor for this article. I am very grateful to my advisors Alberto Alesina, Raj Chetty, Michael Kremer, and Andrei Shleifer. I thank Laura Abramovsky, Tim Besley, Michael Best, Ciro Biderman, Raluca Dragusanu, Itzik Fadlon, François Gerard, Nathan Hendren, Nate Hilger, Martin Kanz, Asim Khwaja, Henrik Kleven, Camille Landais, Anders Jensen, Olivia S. Mitchell, Sendhil Mullainathan, Arash Nekoei, Dina Pomeranz, Francisco Queiro, Tristan Reed, Heather Schofield, Edson Severnini, Joel Slemrod, Sandra Sequeira, Ian Tomb, Matthew Weinzierl, and Danny Yagan for invaluable comments and advice. I also thank seminar and conference participants. I am extremely grateful to Adrea Calabi, André Luis Grotti Clemente, Igor Baremboin, and Euripedes De Oliveira for the opportunity to work with the Department of Finance of Sao Paulo (SEFAZ/SP). I am very thankful to Paulo Yamada and to the SEFAZ/SP staff for outstanding collaboration. I thank Sabrina Naritomi and Tiffany Blackman for legal advice, and SOX Consult for assistance with the Brazilian tax law. Research support from the Lab for Economic Applications and Policy-LEAP (Harvard University), Lemann Fellowship, Taubman Fellowship (Harvard Kennedy School of Government), David Rockefeller Center for Latin American Studies (Harvard University) is gratefully acknowledged. This work uses anonymized data, and does not necessarily reflect the views of SEFAZ/SP. The authors declare that they have no relevant or material financial interests that relate to the research described in this paper.

Go to https://doi.org/10.1257/aer.20160658 to visit the article page for additional materials and author disclosure statement.

${ }^{1}$ Musgrave (1969) emphasized the historical relevance of tax administration for tax collection. In the policy debate, tax administration and the enforcement capacity of developing country governments are central issues (Slemrod and Gillitzer 2013, Bird and Gendron 2007, International Monetary Fund 2011).

${ }^{2}$ Audit experiments typically detect near zero evasion in income subject to third-party reporting (Kleven et al. 2011, Pomeranz 2015). For instance, wage earners would face a much higher risk of audit relative to the self-employed if they under-report income, as firms typically also report wages paid to the government (Slemrod 2007). More generally, information trails shared with third-parties such as employees, suppliers, banks, or customers could have a deterrence effect even if they are not systematically reported to the government. Evidence from
} 
the dynamics of government revenue among advanced economies during the last century (Gordon and Li 2009; Kleven, Kreiner, and Saez 2016).

Despite the empirical literature on the deterrence effect of third-party reporting, there is little direct evidence on whether changes in availability of information trails can improve compliance and on the mechanisms through which third-party reporting deters evasion, as it hinges on avoiding collusion opportunities among the informed parties. ${ }^{3}$ This paper exploits quasi-experimental variation and unique administrative data on firms and consumers from an anti-tax evasion program in São Paulo, Brazil (Nota Fiscal Paulista, or NFP) that created monetary rewards for consumers to ensure that firms report final sales transactions. The program provides tax rebates and monthly lottery prizes for consumers who ask for receipts, and establishes a direct communication channel between the tax authority and consumers through an online account system, where consumers can verify receipts reported by firms and can act as whistle-blowers by filing complaints.

The program was designed to address the "last mile" problem of the self-enforcing mechanism of the value added tax (VAT). Along the supply chain, the tax credit and debit system of the VAT generates third-party reporting in transactions across firms. $\rrbracket^{4}$ At the final consumer stage, however, these self-enforcing incentives break down since consumers typically derive no direct monetary benefit from asking for receipts. ${ }^{5}$ The NFP policy introduced incentives similar to the VAT for final sales: it aims to affect both the likelihood that a transaction is reported at all, and the accuracy of reporting, since rewards to consumers are an increasing function of the value of receipts. ${ }^{6}$

I begin by laying out a conceptual framework to discuss how incentives to consumers can affect firm behavior. The NFP policy is effectively increasing the availability of third-party information trails through rewards to consumers, but collusion between consumers and firms could hinder the self-enforcing effect of third-party information. However, in order to collude with consumers and continue evading, firms would need to transfer part of evasion rents to consumers through discounts and incur in a fixed cost to set the collusive deal. Moreover, firms would reveal evasion information to many third parties by conditioning the discount on not accurately reporting the transaction to the government. As in Kleven, Kreiner, and Saez (2016), the difficulty in sustaining collusion with a large number of informed

Denmark and the United States suggests that even when income is not subject to systematic third-party reporting, compliance is well below full evasion, which could be explained in part by the existence of derivative information shared with third-parties (Kleven 2014).

${ }^{3}$ This is a well-known issue in the mechanism design literature (e.g., Tirole 1986): once more than one person is informed about evasion then there are many mechanisms that can be used to elicit that information (Besley and Persson 2013). A key assumption in these cases is that there is no scope for collusion among the informed parties. For instance, Yaniv (1993) argues that employers and employees can find mutually beneficial opportunities to reduce their tax liabilities, which would result in limited enforcement effect on self-reports of individual income subject to cross-reporting by firms.

${ }^{4}$ Most countries in the world adopted the VAT instead of sales tax, perhaps because of its enforcement advantage (Keen and Lockwood 2010). Kopczuk and Slemrod (2006) argue that retail sales tax and the VAT are theoretically equivalent, but the VAT has built-in enforcement incentives along the supply chain. Pomeranz (2015) provides empirical evidence for the self-enforcing properties of the VAT in business-to-business transactions.

${ }^{5}$ Slemrod (2007) refers to the enforcement problem at the final consumer stage as the "Achilles' heel" of administering a retail sales tax: if firms collude to under-report transactions, the self-enforcing mechanism can unravel, and may hinder tax collection across the entire chain.

${ }^{6}$ Both the tax rebate and the number of lottery tickets with which consumers are rewarded are a function of the total amount they spend in a given month as detailed in Section IIB. 
economic agents who can act as whistle-blowers might be important to deter evasion. Therefore, the effect of consumer monitoring should be stronger the higher the threat of whistle-blowing, and the more costly it is for firms to match the value of the rewards offered by the government.

In order to empirically investigate the extent to which rewards to consumers can affect firm compliance, I construct unique administrative data on firm-level monthly tax returns, monthly individual-level data on requested receipts and overall participation in the NFP program, based on administrative records from the tax authority of the state of São Paulo..$^{7}$ I divide my analysis into four parts. First, I study the effect of consumer monitoring on firms' compliance by exploiting variation in the intensity of exposure to the policy. I compare reported revenue changes in firms that sell mostly to final consumers (retail) versus firms that sell mostly to other firms (wholesale). I estimate that reported revenue in retail increased on average by 21 percent over 4 years as a result of NFP. This estimate is likely to be a lower bound for the effect of the program, given that wholesale firms may also have been affected by the change in consumers' decisions to ask for receipts. $\square^{8}$

Second, I shed light on mechanisms by examining the implications from the conceptual framework for firms subject to higher whistle-blower threats, and by discussing the role of rewards offered by the government on consumer participation in the enforcement policy. I find evidence consistent with the argument that collusion might be costly and difficult to sustain if consumers can blow the whistle. Firms in sectors that typically have a high volume of transactions and sell small ticket items are affected more, consistent with fixed costs to collude with consumers. Also, firms in sectors that are characterized by a large number of different consumers, that would be more exposed to potential whistle-blowers, are relatively more affected by the consumer rewards program. Furthermore, I link consumer participation to firm compliance by exploiting the timing of consumers' whistle-blowing and find that firms report 7 percent more receipts and 3 percent more revenue after receiving the first complaint.

Third, I turn to the effects of rewards on consumer participation. As suggested by the conceptual framework, the more consumers value the rewards, the more costly it will be for firms to try to match the government's incentives. I exploit variation from lottery prize rewards from NFP to analyze changes in the number of receipts that individuals ask for and the total value of receipts. I find that consumers condition their decisions to ask for receipts on past lottery wins. Even when prizes are as small as US\$5, winners ask for receipts more often for at least six months after the lottery result relative to non-winners with the same odds of getting a prize. In addition, I find an increase of US\$16.14 (SE 3.08) in the total value of receipts during the six months after the lottery, so the effect cannot be attributed to the cash prize alone. The results are consistent with the possibility that lotteries amplify consumer engagement due to behavioral biases.

\footnotetext{
${ }^{7}$ A number of measures were taken to de-identify the data in order to protect confidential tax records.

${ }^{8}$ Wholesale firms can sell to final consumers directly, in which case the rewards program applies. Additionally, improving compliance among retail firms can affect compliance by wholesalers through the self-enforcing mechanism of the VAT.
} 
In the final part of the paper, I discuss implications for tax policy. First, I analyze how tax liabilities were affected by the policy. An increase in reported revenue could, in principle, be circumvented by adjustments in reported expenses. I find that firms significantly increase reported inputs, but not enough to offset the effect of reported revenue on value added. I estimate that the NFP program increased reported tax liabilities by 25.9 percent. However, through the incentives to consumers, governments are foregoing a fraction of both marginal and infra-marginal revenue, so it is not obvious ex ante that a positive effect on tax revenue would be sufficient to cover the costs of the program. I calculate that tax revenue increased by 9.3 percent net of rewards. Finally, I discuss welfare implications of consumer reward policies by considering social costs and benefits, and the impacts on firms, consumers, and the government.

This paper contributes to the vast literature on tax enforcement (e.g., Andreoni, Erard, and Feinstein 1998; Slemrod and Yitzhaki 2002) by providing evidence on how a policy can tap into local information on tax evasion, and leverage frictions to collusion in order to increase compliance in a hard-to-tax sector. In particular, this paper contributes to a growing literature that argues that third-party information is key for compliance (Kleven et al. 2011; Pomeranz 2015; Kumler, Verhoogen, and Frias 2012). Additionally, the paper contributes to the literature on the challenges of tax enforcement in developing countries, which is believed to be a key determinant of countries' choices of tax instruments (e.g., Gordon and Li 2009, Best et al. 2015, Jensen 2019). In particular, a growing strand of the literature sets aside noncompliance due to firm nonregistration at the tax authority, the formal-informal margin, and instead examines noncompliance among formal firms. ${ }^{9}$

The paper also contributes to the policy debate on sales tax enforcement. Many countries adopted policies to reward consumers to address the last mile problem of the VAT. ${ }^{10}$ This paper provides, to my knowledge, the first direct evidence of consumer behavioral responses to rewards from asking for receipts. The results also reinforce existing findings on individual responses to lotteries that are used as levers in other contexts, such as lottery-linked savings (Tufano 2008, Kearney et al. 2010). Moreover, the evidence from the NFP lotteries adds to the literature on the behavioral effects of lottery wins such as the lucky store effect (Guryan and Kearney 2008). More generally, the paper sheds light on the effects of participatory policies used as a monitoring tool.

Finally, the paper contributes to the debate on how other margins of adjustment (e.g., reported expenses) may compensate for an increase in enforcement of revenue reporting. In the context of corporate income tax (CIT), Carrillo, Pomeranz, and Singhal (2017) and Slemrod et al. (2017) find that reported costs substantially

\footnotetext{
${ }^{9}$ De Paula and Scheinkman (2010) argue that better enforcement in the intensive margin of VAT systems can endogenously generate incentives to formalize by creating supply chains of formal firms. See Bruhn and McKenzie (2014) for a review of the literature on the formalization of firms.

${ }^{10}$ For instance, Argentina, Bolivia, Brazil, China, Chile, Colombia, Indonesia, Italy, Portugal, Puerto Rico, South Korea, and Slovakia, among other countries, have introduced policies to address the enforcement problem downstream through monetary incentives (through tax refunds, lotteries, or fines) for consumers to request receipts (Fooken, Hemmelgarn, and Herrmann 2015; Bird 1992; Cowell 2004; Fabbri 2015; Marchese 2009). Wan (2010) argues that a program that turns receipts into lottery tickets in China was effective in raising tax revenue, but the evidence for such policies is mixed (Barroso and Cortez 2007; Mattos, Rocha, and Toporcov 2013).
} 
increase, offsetting to a large extent the profit change from more accurate revenue reporting. In both cases, the cost increase occurred primarily in difficult to verify margins such as "other expenses." In the case of the VAT, the ability to adjust inputs is arguably relatively more limited as a tax credit must be another firms' tax debit. The findings of this paper indicate that reported expenses can be adjusted in a VAT context, but perhaps to a lesser extent than in CIT due to the self-enforcing feature of the VAT.

The remainder of the paper is organized as follows. Section I outlines a simple conceptual framework to guide the empirical analysis. Section II describes the institutional background of the Nota Fiscal Paulista program, the relevant datasets, sample definitions, and summary statistics. Section III investigates the enforcement effect of the introduction of third-party information through consumer rewards on firms' reported revenue, and Section IV sheds light on mechanisms suggested by the conceptual framework regarding whistle-blower threats, collusion costs, and the value of monetary rewards. Section $\mathrm{V}$ examines the impact on expenses and tax revenue, and discusses implications for tax policy. Section VI concludes.

\section{Conceptual Framework}

I begin the analysis by describing a simple conceptual framework that examines the degree to which consumer monitoring can affect the evasion decision by firms. I use a variant of the Allingham and Sandmo (1972) framework discussed by Kleven et al. (2011), in which the probability that a taxpayer is caught evading depends on the audit rate and the probability of detection conditional on an audit. First, I present a baseline case with government monitoring only. Then, I introduce consumer monitoring as an additional enforcement tool that gives rewards for consumers to ensure firms report final sales transactions, and allows consumers to act as whistle-blowers. In this case, firms may continue evading by colluding with consumers. In doing so, however, firms get a lower benefit from evasion and reveal to a number of third-parties evasion information that the government may access through whistle-blowers. As a result, firms will increase compliance. ${ }^{11}$

\section{A. A Tax Evasion Model}

Consider a risk-neutral firm that pays a tax $\tau \in[0,1]$ proportional to their reported revenue $Y \geq 0$. Suppose that firms sell a single product, and that each firm has $N$ consumers who each make one purchase which generates revenue $\bar{y} \geq 0$. Firms have a true pretax revenue $\bar{Y}=N \bar{y}$, and choose to report revenue $Y$ to maximize profits $\pi$, which depends on enforcement policies.

Government Monitoring Only.-Let $p \in[0,1]$ be the probability of detection faced by the firm. Similarly to Kleven et al. (2011), I assume that the audit probability is increasing in the amount evaded, and that the probability governments detect

\footnotetext{
${ }^{11}$ I take a positive approach to understand the effects of different monitoring tools on firms' evasion decision. For a normative approach, see Arbex and Mattos (2015), who investigate how the Ramsey equation is modified once consumers are rewarded to ask for receipts.
} 
evasion is a product of government audits and the likelihood that the government will uncover evasion by taxpayers during an audit. Kleven (2014) argues that the more derivative information from various third-party sources is available to tax enforcement, the more compliance we observe despite low audit rates. The intuition is that the more information the government has about the firm, the easier it is to detect evasion conditional on an audit (Slemrod 2007).

Let $a(E) \in[0,1]$ be the audit probability, $E=\bar{Y}-Y$ be the total evasion by firm, and $d \in[0,1]$ be the ability of the government to detect evasion in an audit. The probability of detection faced by the firm can be written as $p \equiv a(E) d, p^{\prime}(E)=a^{\prime}(E) d>0$. If the firm is caught evading, the government applies a fine $\theta \geq 0$ in proportion to the evaded tax $\tau(\bar{Y}-Y)$. For simplicity, assume that in the absence of monetary incentives, consumers do not ask for receipts and have no impact on the evasion decision of firms. Thus, firms report revenue $Y$ to maximize

$$
\pi=(\bar{Y}-\tau Y)(1-p)+[(1-\tau) \bar{Y}-\theta \tau(\bar{Y}-Y)] p
$$

An interior optimal solution $Y^{*}$ satisfies the first-order condition $d \pi / d Y=0: 12$

$$
\left[a(E)+a^{\prime}(E) \cdot E\right] d(1+\theta)=1 .
$$

The right-hand side of equation (2) is the marginal benefit of evading an extra dollar, and the left-hand side is the marginal cost of evading that extra dollar. As discussed in Kleven et al. (2011), the firm that evades an extra dollar incurs in a higher probability of audit of all infra-marginal dollars evaded. Firms choose the optimal $Y^{*}$ that satisfies equation (2), and $Y^{*}$ will be increasing in the detection probability $d .13$

Adding Consumer Monitoring.-For simplicity, I assume that if a firm issues a receipt, that transaction will be reported correctly. ${ }^{14}$ Now, suppose the government creates targeted incentives for consumers to ask for receipts. Consider the case where consumers are rewarded with $\alpha \in[0,1]$ of the tax $\tau$ firms pay on the transaction reported to the government. Consumers can ensure they receive this reward by requesting a receipt, and they can act as whistle-blowers by informing the government about firms' noncompliance.

Let $\kappa(\alpha)$ be how much consumers value the rewards $\alpha$ from the program, where $\kappa(\alpha) \geq 0$ and $\kappa^{\prime}(\alpha) \geq 0$. Let $\kappa(0)=0$, in which case we are back to government

\footnotetext{
${ }^{12}$ The second-order condition is $2 a^{\prime}(E)+a^{\prime \prime}(E) E>0$. It is necessary and sufficient that $E a(E)$ is convex, which is essentially the same condition as in Kleven et al. (2011).

${ }^{13}$ Given the convexity of $E a(E), \partial Y^{*} / \partial d=\left[a(E)+a^{\prime}(E) \cdot E\right](1+\theta) /\left(2 a^{\prime}(E)+a^{\prime \prime}(E) E\right)>0$.

${ }^{14}$ Receipts are an important tool for enforcement, which is the main rationale for consumer rewards programs in the first place. Therefore, I will refer to firms' decision to issue a receipt as being equivalent to a decision to report a transaction. It is possible that even after issuing a receipt, firms may try to erase those records (using zappers or phantom ware, for instance), but it is costly. In the São Paulo context, billing machines that issue receipts with time stamps and serial codes were already widespread since the early 2000s. Across the world, the adoption of Electronic Billing Machines that send data in real time to governments are making such ex post changes quite difficult.
} 
monitoring only. ${ }^{15}$ For instance, if consumers are unaware of the program, $\kappa(\alpha)$ can be close to zero even if $\alpha>0$. If consumers enjoy participating in the program above and beyond the monetary value attached to it, $\kappa(\alpha)>\alpha$. This could occur, for instance, if consumers enjoy playing the lottery or value engaging in a tax compliance program. There could also be a framing effect from rewards: a tax rebate, for instance, may help segregate small gains, making it more valuable than a discount of the same amount (Thaler 1999). 16

As the government is rewarding consumers with a fraction of what firms pay in taxes, firms and consumers could potentially agree to a mutually beneficial deal and not issue receipts. ${ }^{17}$ For simplicity, assume that firms make a take it or leave it discount offer to consumers to continue reporting $y$ instead of the true amount $\bar{y}$, and that consumers accept a discount deal that matches the difference with respect to the government's reward $\kappa(\alpha) \tau(\bar{y}-y)$.

It is important to note that not only must the firm share part of their evasion rents with the consumer, the firm reveals to a third party that it evades taxes by conditioning the discount on not reporting the true amount of the transaction. Consumers, therefore, become informed third parties. As consumers can act as whistle-blowers, governments may gain access to relevant information about firms' evasion. Thus, the firm might face an increased detection probability if consumers cannot commit not to whistle-blow. 18

Kleven (2014) argue that a key deterrent of collusion is the sheer number of internal or external parties to which a firm that evades taxes exposes itself. I consider the case where there is a positive probability of a random shock between the parties that can trigger a consumer to blow the whistle. A random shock could be generated by some conflict between the consumer and the shopkeeper, or a moral concern of the consumer. Therefore, the larger the number of consumers $N$, the higher the additional risk of detection introduced by consumers that may act as whistle-blowers.

Assume $\varepsilon>0$ is the probability that such a random shock occurs; let $\varepsilon$ be i.i.d. across consumers. Assume that if one consumer blows the whistle on the firm the information she provides allows the government to detect evasion with certainty in an audit, and that all the $N$ consumers may blow the whistle. The intuition is that consumers are gathering relevant information about evasion conducted by firms that can improve the enforcement capacity of the government for a given audit rate. So the ability of the government to detect evasion under consumer monitoring will be a function of $N$ and can be written as $d_{c}(N)=1-(1-d)(1-\varepsilon)^{N}, d_{c}^{\prime}(N)>0$.

\footnotetext{
${ }^{15}$ If $\kappa(0)>0$, i.e., consumers value compliance per se, the policy could have an effect even if there are no monetary rewards, just a whistle-blower channel. In this case, the problem of the firm would be similar as it would try to match this taste for compliance with a discount, and providing a tool to whistle-blow firms could be valuable to create credible threats of $\varepsilon>0$.

${ }^{16}$ Based on prospect theory, framing outcomes separately could yield larger gains as the gain function is steepest at the origin. The utility of a small gain, therefore, could exceed the utility of slightly reducing a large loss.

${ }^{17}$ Tirole (1986) discusses the collusion problem in auditing contracts in which a group of informed parties (the auditor and the agent) can manipulate the information reported to the principal. This context is also similar to the case of corruption with theft in Shleifer and Vishny (1993).

${ }^{18}$ In the empirical context, it is particularly salient that a collusive deal will allow the firm to evade taxes since the government is giving a reward for consumers to ask for receipts in a campaign against tax evasion. Also, as will be described in detail in Section II, consumers can be whistle-blowers by filing complaints about specific firms to the government through a website.
} 
Therefore, firms face an increased probability of getting caught $p_{c}$ given by $p_{c}=a(E)\left[1-(1-d)(1-\varepsilon)^{N}\right] \cdot 19$

Finally, suppose that when firms make an offer to a consumer, they pay a fixed cost $\rho>0$. The fixed cost can be thought of as a concealment cost paid to reach a collusive deal in each transaction. I assume that, if firms evade taxes, they adopt a collusion policy that applies to all transactions and must pay $\rho>0$ as concealment cost. In online Appendix C, I discuss an alternative case in which firms only collude with a fraction of the transactions. The main point of collusion costs is to emphasize how frictions from concealing a collusive deal with a large number of parties can contribute to increase compliance.

Now firms choose $Y$ to maximize 20

$$
\pi=(\bar{Y}-\tau Y)\left(1-p_{c}\right)+[(1-\tau) \bar{Y}-\theta \tau(\bar{Y}-Y)] p_{c}-\kappa(\alpha) \tau(\bar{Y}-Y)-\rho N
$$

As mentioned above, under the new policy, firms have to transfer part of the evasion rents to consumers through discounts. An interior optimal solution $Y^{* *}$ satisfies the first order condition $d \pi / d Y=0$,

$$
\left[a+a^{\prime}(E) \cdot E\right] d_{c}(1+\theta)=1-\kappa(\alpha) \text {. }
$$

The equation highlights two ways in which the firm's evasion decision is affected by rewards to consumers. First, the marginal benefit of evading an extra dollar is reduced by $\kappa(\alpha)$. Therefore, the degree to which consumers value the program enter as an extra penalty for each dollar evaded. In this case, the more consumers value the rewards $\alpha$, the higher this extra-penalty will be. Second, if consumers cannot commit not to whistle-blow, the new detection probability will be increasing in the number of consumers $N$ as it increases the chances that consumers will inform the government about the evasion activity of firms.

The cost of collusion $\rho N$ would affect the extensive margin decision between evasion and full compliance, but not the intensive margin of compliance. In particular, if the payoff of full compliance and the collusion cost $(1-\tau) \bar{Y}+\rho N$ is larger than the expected value of taking the evasion gamble, the firm would shift to full compliance. ${ }^{21}$ Note that the value of the transaction $\bar{y}$ will matter for this policy because firms with the same true revenue $\bar{Y}$ may be affected differently: firms that sell small ticket items (low $\bar{y}$ ) would have to collude in a larger number of transactions for a given total

\footnotetext{
${ }^{19}$ It is possible that whistle-blowers affect the audit probability as well, and an alternative model could be written in line with Kleven, Kreiner, and Saez (2016) that assumes that one whistle-blower triggers a full audit. The empirical implications in the next sections would be similar. Because information about audit rates or audit strategies are strictly confidential, it is not possible to distinguish in the data changes in audit rate from changes in detection ability conditional on audit. The conceptual distinction is useful, nonetheless, to illustrate how information from consumer monitoring can augment the effectiveness of government audits even if there are no changes in audit rates, which implies a higher risk of evasion faced by taxpayers.

${ }^{20} \mathrm{I}$ assume that if the firm is audited, the government will consider as tax evasion the amount not reported based on the posted price $\bar{y}$, not the discounted price. Therefore, $\bar{Y}$ will be the true revenue of the firm, instead of the revenue net of transfers to consumers.

${ }^{21}$ In online Appendix C, I consider an alternative model in which firms can selectively collude with some consumers but not others to minimize such fixed costs. In this case, the fixed cost will affect the intensive margin decision of firms to evade taxes. The key insights, however, can be achieved with this simpler version where firms have a collusion policy that applies to all transactions.
} 
revenue $\bar{Y}$. This effect should be empirically similar to the increased probability of getting caught evading through whistle-blowers, although the whistle-blower threat depends on the total number of different consumers, whereas the collusion cost effect depends on the sheer number of transactions as I discuss below.

Comparative Statics and Discussion.- The first-order conditions in both (2) and (4) can be expressed as $a+a^{\prime}(E) \cdot E=c$, where $c$ is a function of parameters that are changing with the policy. With government monitoring only, $c=1 /(d(1+\theta))$. With consumer monitoring, $c=(1-\kappa(\alpha)) /\left(d_{c}(1+\theta)\right)$. Changes in $c$ translate into comparative statics of $E^{*}$ : if $c$ increases, the optimal evasion will also increase. ${ }^{22}$ In this subsection, I discuss how each component of the policy affects the evasion decision of firms and its implications.

Value of Rewards: In a collusive deal, firms try to match the value of rewards provided by the government through a discount. The reward to consumers reduces $c$ and, therefore, decreases evasion. In particular, the higher the reward $\alpha$ and the more consumers value the rewards $\kappa(\alpha)$, the higher the extra-penalty per dollar evaded will be. In the empirical setting, the reward has a lottery component so it is possible that its value is actually higher than the monetary expected value of the program's reward $(\kappa(\alpha)>\alpha)$. As I discuss in Section IVB, a taste for gambling or behavioral biases in assessing the odds of winning prizes could inflate the perceived value of lottery rewards, making it particularly costly for a firm to replicate the government's reward through a discount. The rewards, therefore, could have an effect on compliance even without a whistle-blower channel (i.e., unchanged detection ability of the government).

Further, the fact that the valuation of the benefit may differ from the monetary rewards could introduce a higher fixed cost in reaching a collusive deal. In the simple framework considered above, a larger $\rho$ could push firms to switch to compliance. Considering a simple extension where the fixed cost $\rho$ for colluding with consumers increases with the gap between the perceived size of the reward and its monetary value, i.e., if $\rho(\kappa(\alpha)-\alpha)$ and $\rho^{\prime}(\kappa(\alpha)-\alpha)>0$, it could be the case that a reward scheme that is not straightforward for a firm to mimic (e.g., lottery) is relatively more cost-effective for the government. The impact on consumers' welfare, however, depends on why there is such bias in the perceived value of rewards, and whether it affects "experienced" utility or only "decision" utility. I revisit this discussion in Section V.

Volume of Consumers: The enforcement change introduced by consumer monitoring is stronger the larger the increase in the detection probability. This comparative statics follows from a drop in $c$ as $d_{c}>d$. The increase in compliance should increase with the volume of consumers for a given firm size or true revenue $\bar{Y}$. This distinction between firm size and volume of consumers is relevant to shed light on a mechanism through which third-party information affects compliance: exposure to whistle-blower threats can decrease evasion.

\footnotetext{
${ }^{22}$ The necessary assumption for monotonicity $\partial E^{*} / \partial c=1 /\left(2 a^{\prime}(E)+a^{\prime \prime}(E) E\right)>0$ is that $E a(E)$ is convex, which is the same convexity assumption discussed above for the second-order condition.
} 
Volume of Transactions and Size of Transactions: In the simple framework proposed above, there is one transaction for each consumer. Considering the case of multiple transactions per consumer, the number of transactions could matter through a different mechanism than the number of consumers: the larger the number of transactions a firm has, the more this policy may increase compliance as the fixed costs disproportionally affect firms that need to collude multiple times for a given firm size $(\rho N)$. Similarly, firms that sell small ticket items should be affected relatively more for a given firm size.

Whistle-Blowers: If firms engage in a collusive deal but believe that consumers will likely never blow the whistle, perhaps because they have never seen a consumer blow the whistle, they may perceive $\varepsilon$ as being lower than it actually is. If this is the case, once firms observe consumers blowing the whistle, they may update upward their beliefs about $\varepsilon$, which reduces $c$ and increases compliance. The data allow me to directly observe how firms react once they learn a consumer blew the whistle.

Firm Size: Even absent of consumer monitoring, larger firms arguably would be more at risk of getting caught for a given evasion level due to the number of internal or external informed parties (e.g., employees, buyers, suppliers) that may have information on tax evasion. In the model above, it would be as if $d$ was higher for larger firms to begin with and, therefore, their baseline level of compliance should be higher (higher $d$ lowers $c$ ). In other words, firm size alone could already generate variation in baseline exposure to whistle-blower threats (e.g., from the total number of informed third parties that firms interact with). The consumer rewards policy introduces a new set of informed third-parties: consumers that will ask for receipts and potentially learn about evasion (e.g., if they observe collusion through conditional discounts offers). In this case, the effect of the policy would be relatively larger for firms with a lower baseline $d$, which can be tested in the data.

Government Revenue: The government transfers to consumers $\alpha \tau Y^{* *}$. It is important to notice that because the government cannot distinguish between marginal and infra-marginal sales, it rewards infra-marginal sales as well. If we restrict attention to revenue from taxes only (without fines), the program should increase tax revenue if $Y^{* *}-Y^{*}>\alpha Y^{* *}$. In other words, government revenue will increase if the tax base increase is larger than the tax base the government is forgoing. This implies that the percentage change in tax revenue will have to be at least $\left(Y^{* *}-Y^{*}\right) / Y^{*}>\alpha /(1-\alpha)$ to generate an increase in government revenue. If the baseline level of compliance is very low, the program would be particularly attractive. Also, if higher compliance can be achieved without rewarding every single transaction (e.g., imperfect take-up by consumers), the program will be more cost-effective. I revisit this discussion in Section V. ${ }^{23}$

\footnotetext{
${ }^{23}$ Note that, for simplicity, I am assuming here that the increase in tax collection is proportional to the increase in reported revenue as it is modeled as a sales tax. The goal of this simplification is to flesh out how sales reporting, the margin directly affected by the policy, can change. The same logic would carry over to the VAT if the tax base $Y$ is the reported value added, and changes in reported expenses cannot fully offset changes in reported revenue. This is true in the data as I analyze in Section V.
} 


\section{Institutional Background and Data}

This section provides institutional background on the Nota Fiscal Paulista (NFP) policy, and the details of the program that are important for the empirical analysis. First, I briefly introduce the relevant features of the Brazilian tax system and the NFP policy. Then, I describe the datasets I use and sample definitions. ${ }^{24}$

\section{A. Institutional Background}

The State of São Paulo is the largest state in Brazil. It accounts for 34 percent of the country's GDP, and has a population of 42 million people. The metropolitan area of São Paulo is the second-most populous in the Americas. The state of São Paulo depends mostly on its own tax revenue, as opposed to federal transfers.25 States in Brazil have two main tax instruments: a tax on goods and certain services (ICMS) and a property tax on motor vehicles (IPVA). ${ }^{26}$ The ICMS is a value added tax (VAT), and it is the most important source of revenue in São Paulo. Because the ICMS is a state-level tax in Brazil, its legislation and enforcement policies are determined by the states. The tax base includes goods and some services, the most common ICMS rate is 18 percent over the valued added, which is computed through a credit-invoice method. ${ }^{27}$ As is common in VAT across the world, there is a threshold below which firms pay taxes on gross revenue instead of the value added (Keen and Mintz 2004). Firms that have yearly gross revenue of less than US\$1.2 million can choose to be in a simplified tax regime called SIMPLES in which firms pay taxes based on gross revenue. The ICMS average rate in the SIMPLES is 3.5 percent of gross revenue. ${ }^{28}$ The majority of the tax collected in retail comes from VAT firms (over 85 percent).

In 2007 the state of São Paulo collected US\$27.2 billion with the ICMS, equivalent to 7.6 percent of the state's GDP. Overall, tax revenue in Brazil is high for developing country standards. Considering all taxes, tax revenue amounts to 34 percent of the country's GDP (International Monetary Fund 2011). Nonetheless, there are many reasons to believe that tax compliance is not perfect in Brazil. According to La Porta and Shleifer (2014), estimates of size of the country's informal economy range from 19 percent to 34 percent of GDP. Unregistered firms are invisible to the

\footnotetext{
${ }^{24}$ Throughout the paper I will convert Brazilian reais to dollars using US $\$ 1=\mathrm{R} \$ 2$ exchange rate, which is the average exchange rate during the period of analysis (2004-2011).

${ }^{25}$ When the NFP policy was implemented in 2007, São Paulo's own tax revenue was 75 percent of its total revenue according to the balance sheets of the Brazilian Treasury Department. Moreover, Haddad et al. (2011) argue that São Paulo state generated more than 40 percent of the federal tax revenue, while receiving less than 35 percent of federal transfers in 2005. Federal taxes include, for instance, individual and corporate income taxes, payroll taxes, and taxes on manufactured products.

${ }^{26}$ The IPVA (Imposto sobre Propriedade de Veículos Automotores) and ICMS (Imposto sobre Circulação de Mercadorias e Serviços) typically account for 95 percent of the total tax collected by states. The other two sources of tax revenue are a tax on bequests and donations called ITCMD (Imposto sobre Transmissão Causa Mortis e Doações) and fees for public services.

${ }^{27}$ On a monthly basis, firms declare how much taxes they owe based on their taxable sales (debits) and how much credit they have from purchases of goods and services taxed by ICMS (credits). The difference between tax debits and credits determine a firm's tax liability. For the majority of goods, the ICMS rate is 18 percent. In some cases, a reduced rate of 7 percent or a higher rate of 25 percent is applied. The tax base covers goods and a few services, such as restaurants and electricity provision. Most services are part of the tax base of a municipal sales tax.

${ }^{28}$ For more details about SIMPLES, see de Paula and Scheinkman (2010) or Monteiro and Assunção (2012).
} 
tax authority, and no taxes are levied directly on them. Formal firms have to report their activity to the tax authority on a monthly basis, and pay the ICMS in relation to their reported activity. Despite the tax authority's monitoring, compliance by formal firms is also limited. In the World Business Environment Survey 2003, on average Brazilian formal firms claim that 20-30 percent of sales are not reported to the tax authority by a typical firm in their area of activity. ${ }^{29}$ When the NFP program was implemented, the Secretary of Finance of São Paulo at the time argued that the retail sector in the state evaded taxes on approximately 60 percent of its sales. ${ }^{30}$

\section{B. The Nota Fiscal Paulista Program}

The Nota Fiscal Paulista (NFP) program was created by the government of the state of São Paulo in October 2007 in order to reduce tax evasion of the state's VAT, and to foster a culture of tax compliance. ${ }^{31}$ The idea behind the NFP program is to use consumers as "tax auditors" by introducing targeted incentives for consumers to ensure that firms report final sales. The incentives provided by the program replicate the VAT self-enforcement already in place for business to business transactions; rewards are increasing in the value of the purchase such that buyers have incentives to ask for receipts, and to make sure that the value of the purchase is reported correctly by the supplier. Therefore, the NFP program directly affects two forms of under-reporting: (i) firms may not report a transaction at all, or (ii) firms may falsely claim a lower transaction value. ${ }^{32}$

In a nutshell, the program introduced the possibility of identifying an individual taxpayer number-henceforth, referred to as Social Security Number (SSN) equivalents - on each receipt, and created a system of tax rebates and monthly lotteries so that final consumers have incentives to request receipts with their SSN. Since the process of reporting receipts to the tax authority is done by firms, and the consumer's $\mathrm{SSN}$ is attached to it, consumers do not need to send their receipts to the tax authority to get the rewards, which markedly reduces consumer participation costs. Consumers have to create an online account at the tax authority's website, which allows them to collect rewards and cross-check the receipts issued with their SSNs. The online system also allows consumers to file complaints about specific firms, which introduces a threat that consumers may act as whistle-blowers (see online Appendix Figure A1).

Implementation: The reward system was introduced along with a system of transaction reporting through which firms were required to send electronically to

\footnotetext{
${ }^{29}$ The question in Batra, Kaufmann, and Stone (2003, p. 138) is "Recognizing the difficulties many enterprises face in fully complying with taxes and regulations, what percentage of the total sales would you estimate a typical firm in your area of activity keeps off the books: 1 (none); 2 (1-10 percent); 3 (11-20 percent); 4 (21-30 percent); 5 (31-40 percent); 6 (41-50 percent); 7 (over 50 percent)." In the case of firms that sell to final consumers, the tax evasion problem is likely to be more severe since firms are smaller than in upstream sectors. In the same survey, the percentage of sales that are under-reported or not reported at all reaches 30-40 percent among smaller firms in Brazil.

${ }^{30}$ Márcia De Chiara, "Sonegação de impostos equivale a 30\% do PIB," Estado de São Paulo, September 8, 2007.

${ }^{31}$ The NFP policy was framed as an incentive to improve tax morale. The official slogan of the policy was "Incentive Program for Fiscal Citizenship" (Programa de Incentivo à Cidadania Fiscal).

${ }^{32} \mathrm{~A}$ common way to evade taxes in Brazil is to under-report the value of a sale. This type of evasion is informally known as "meia-nota" or "half-receipt" (do Amaral et al. 2010).
} 
the tax authority all receipts they issue, with or without a SSN. Previously, firms only reported monthly aggregated information and were required to keep all the supporting documents and receipts in their books. With the new system, firms were also required to send the government individual sales information on a monthly basis. ${ }^{33}$ Importantly, this new system did not change the technology of receipts issued by retail firms during the period of analysis (2004-2011). Billing machines that issue receipts with time stamps and serial codes (called Coupom Fiscal in Brazil) were already widespread in São Paulo in the early 2000s, and billing machines with realtime electronic transmission of receipts directly to the tax authority (called Nota Fiscal de Consumidor Eletrônica in Brazil), which can be an important step to reduce tax evasion (see Eissa et al. 2014), only started being introduced in São Paulo in 2015. Therefore, the requirement to send disaggregated sales information alone, without incentives to consumers, should not change firm compliance behavior: firms could simply send to the tax authority information on individual transactions they were already reporting in their official books in the end of each month. 34

Eligibility: The government leveraged the fact that SSNs are not considered sensitive information in Brazil. ${ }^{35}$ Any person that holds a Brazilian SSN equivalent is eligible to participate in the program. ${ }^{36}$ No preregistration is needed for consumers to be eligible for tax rebates, but consumers must create an online account at the tax authority's website to be rewarded with lottery tickets for monthly cash prizes.

The Reward System: At the moment of purchase, the consumer may ask for the receipt, and give the cashier her SSN. Firms must send all receipts, with or without SSNs, to the tax authority on a monthly basis. As the tax authority receives the receipts, it creates an account for each SSN where it stores all receipt information and the tax rebates due from each receipt. If the consumer has an online account and has opted in for lotteries, the system also automatically generates a lottery ticket for every total of US\$50 spent. Therefore, it does not matter if the US\$50 comes from 1 receipt or 50 receipts of $\$ 1$, which also means that the lottery tickets are not attached to specific purchases or shops. During the registration, a consumer may also opt to receive an email every time a receipt is issued with her SSN. The online account displays how much consumers are rewarded for each transaction, and has tabs where a consumer can click to manage rewards and file complaints. Panel A of online Appendix Figure A1 shows an online account example, and panel B displays a receipt with a consumer's SSN.

\footnotetext{
${ }^{33}$ The system is called TD-REDF (Transmissor de Dados para o Registro Eletrônico de Documento Fiscal, or Data Transmitter for Electronic Registration of Fiscal Document).

${ }^{34}$ In addition, during the period of analysis, product codes and bar codes were not standardized so the itemized information was not used beyond the total value reported in each receipt that was used to calculate the rewards.

${ }^{35}$ For instance, the Brazilian SSN equivalent $(\mathrm{CPF})$ is written on checks under the signature line, and consumers are frequently asked for their CPF in business transactions. Also, Brazilians have multiple identification numbers that make identity theft more costly: individual identification, taxpayer number, a voter identification, a social security identification, among others.

${ }^{36}$ Throughout the paper I will refer to the CPF (Cadastro de Pessoa Física) as SSN. I will focus on CPF holders only. They are the overwhelming majority of participants in the program. Some NFP participants have a CNPJ (Cadastro Nacional de Pessoa Jurídica), which is a SSN for firms. Charitable institutions and condominiums, for instance, also have CNPJ and receive the exact same benefits as final consumers.
} 
Tax Rebates: For a given receipt, consumers receive a tax rebate of 30 percent of the VAT paid by the final sale establishment in a month, i.e., it is only a share of the taxes paid by the retailer, not the total tax collected along the supply chain, shared among all consumers of that establishment who provided their SSN that month in proportion to their expenditure in that establishment and month. The calculation of the benefit, thus, is a function of an entire month's worth of SSN receipts and resultant tax paid by the final sales establishment. ${ }^{37}$ On average, the tax rebate is around 1 percent of the total value of the purchase. ${ }^{38}$

Lotteries: NFP has held monthly lotteries since December 2008. For every US\$50 a consumer spends in NFP receipts per month, she receives one lottery ticket. ${ }^{39}$ If the consumer opts in for these lotteries while enrolling online, lottery tickets are automatically generated based on the consumer's total expenditures in NFP receipts as described above. Lottery draws are held around the fifteenth of each month, and each month 1.5 million prizes are distributed on average. Most prizes range from US\$5 to US $\$ 25$, and there are usually three large prizes from US $\$ 15,000$ to US $\$ 500,000$. On average, the expected value of a lottery ticket is 0.1 percent of the total purchase.

Collecting Rewards: Rewards can be (i) directly deposited into the consumer's bank account, (ii) used to pay other state taxes, (iii) transferred to another person with an online account or to a charity. Consumers must have an online account to manage the rewards. Tax rebates are disbursed biannually. In April, tax rebates from July to December of the previous year are made available to consumers; in October the tax authority disburses tax rebates from purchases between January and June of the same year. Lottery prizes can be collected soon after the results are released. Consumers have up to five years to claim the benefits.

Complaints: Consumers may file complaints regarding a purchase made at a specific establishment up to the fifteenth of the month following the purchase. The consumer must identify the establishment and select a reason for the complaint from a five-option menu: (i) the establishment did not issue a receipt; (ii) the establishment refused to write the consumer's SSN on the receipt; (iii) the establishment issued the receipt but did not register it electronically; (iv) there is a discrepancy between the information on the receipt issued to the consumer and the receipt registered

\footnotetext{
${ }^{37}$ If two consumers buy the same total value in the same shop and month they will receive the same tax rebate even if they bought different goods that may be taxed differently. This is partially due to the fact that the tax authority can only use the total value of the receipt to calculate the rebate shares of each individual since the itemized information in the receipt was not standardized in the period of analysis. More precisely, if the firm has $N$ consumers in a month, the benefit consumer $i$ receives from an NFP receipt depends directly on the total ICMS collected from establishment $e$ in month $m\left(I C M S_{e m}^{\text {total }}\right)$, the total value of NFP purchases associated with consumer $i$ and establishment $e$ in month $m\left(V_{\text {iem }}\right)$ and inversely on the total value of NFP purchases in establishment $e$ in month $m\left(\sum_{j=1}^{N} V_{j e m}\right)$. Also, there is a cap on how much an individual consumer can receive: 7.5 percent of the total expenditure, which is 30 percent of the highest VAT rate (of 25 percent). Thus, TaxRebate ime $_{\text {e }}$ $=\min \left\{0.3 \cdot\left[I C M S_{\text {em }}^{\text {total }} \times\left(V_{\text {iem }} / \sum_{j=1}^{N} V_{\text {jem }}\right)\right], 0.075 \cdot V_{\text {iem }}\right\}$.

${ }^{38}$ The rebate value is 30 percent of the tax collected from the shop that sold the item. This is consistent with the fact that the value of taxes paid is 4 percent of the revenue on average. Therefore, for every dollar that she spends, she will get around 1 percent of cash rebate.

${ }^{39}$ The lottery draw in month $m$ uses lottery tickets generated by expenditures in month $m-4$. This 4-month gap is necessary in order to make sure that all disputes over missing or incorrect receipts are resolved before the lottery.
} 
electronically at the tax authority; and (v) other reasons. ${ }^{40}$ Consumers receive a part of the fines paid by the firm as rewards instead of the usual monetary reward when they file a complaint that escalates to a fine. I do not observe, however, the consequences of a given complaint. In the empirical analysis, I therefore use all complaints.

Fines: Firms that do not issue the NFP receipt correctly are subject to penalties and potentially more comprehensive audits by the tax authority. Under tax law, firms can pay up to 100 percent of the evaded tax, and there are additional penalties for misreporting documents and receipts. ${ }^{41}$ If a firm issues a receipt with an individual SSN and misreports the transaction, the process of punishing firms is straightforward if the consumer has a SSN receipt as proof of purchase. ${ }^{42}$ In this case, there are fines applied by the consumer's protection bureau PROCON (Fundação de Proteção e Defesa do Consumidor).

Time Line: NFP was implemented in the retail sector between October 2007 and December 2008. The tax rebate system and electronic submission of receipts was phased-in by groups of sectors between October 2007 and May 2008. The online system to file complaints was available starting in October 2008; the first lottery draw was in December 2008. In April 2009, the tax authority disbursed tax rebates for the first time from all purchases since October 2007, and every 6 months thereafter the government disbursed tax rebates according to the schedule described above.

During the period of analysis from October 2007 to December 2011, 13 million people enrolled online at the tax authority's website, which is 40 percent of the people ages 15 and above in the state. In a given month there are typically 5 million more people asking for SSN receipts than there are online accounts. This gap highlights that the cost to start participating in the program is relatively small: no preregistration is needed since one just needs to have a SSN; but enrolling online might be more costly. Over 40 million people asked for SSN receipts more than once. ${ }^{43}$ Over US\$1.1 billion has been distributed in tax rebates and lottery prizes. During the period of analysis there was a total of 1,151,518 complaints sent to the tax authority by 135,102 different consumers regarding 134,054 different establishments to the tax authority.

\footnotetext{
${ }^{40}$ At that point the consumer does not need to provide evidence to support her complaint, and she can describe details of her case in a text box. The establishment is notified that a complaint was filed via email or letter, and it has 10 days to respond to the complaint. If the consumer is not satisfied with the response, she can file an official complaint. Before this point, the tax authority is not involved in the case. If the consumer decides to file an official complaint, she has to submit supporting evidence by scanning or taking a picture of the receipt or any other proof of purchase. From that point onward, the tax authority and the Consumer Protection Bureau will review the case and apply fines accordingly.

${ }^{41}$ For the legislation on tax penalties, Part IV, Violations Concerning Fiscal Documents and Tax Forms of Decree 45490/00.

${ }^{42}$ Dyck, Morse, and Zingales (2010) find that, in the context of US corporate fraud, access to information and monetary rewards play an important role in encouraging whistle-blowing.

${ }^{43}$ Since any SSN holder in Brazil is eligible for the rewards, people in neighboring states may also participate (the total population of São Paulo is 42 million). Over 500,000 consumers with online accounts are from municipalities outside the state of São Paulo.
} 


\section{Data and Sample Definition}

In this section, I briefly describe each data source, and the summary statistics of the data. First, I present the firm-level data and the main outcomes I examine in Section III. Second, I explain the datasets at the consumer level, and the key variables I use in Section IV. In both cases, I focus on features of the data most relevant for my empirical analysis. Additional details on variable definitions and sample choices can be found in online Appendix B.

Firm Data.-I use administrative data on de-identified establishment-level tax returns and registry information from the Department of Finance of the state of São Paulo, Brazil, from January 2004 to December 2011. ${ }^{44}$ In the empirical for analysis, I restrict attention to the 605,994 firms that submitted tax returns between January 2004 and December 2011, and are registered in a retail or wholesale sector. Also, I aggregate establishments by firms as it is likely that firms maximize their tax planning in a consolidated manner. ${ }^{45}$

Firm Characteristics: From the registry of firms of São Paulo, the main variable I use is the sector of activity. Sectors are defined according to a seven-digit code of the Brazilian National Classification of Economic Activity (CNAE, version 2.1). The retail sectors are all the sectors that start with 47 plus motor vehicle retail under sectors that start with 45 and food services (bars and restaurants) in sectors that start with 56. Wholesale is defined by all sectors that start with 46, plus motor vehicle wholesale under sectors that start with 45 . The sector definition is very detailed; for instance, 472 is Retail food, beverages, tobacco; 4722-9 is Retail meat and fish; and 4722-9/01 is Retail meat (butchery). Throughout the paper, sector refers to the 7-digit definition.

In the empirical analysis, I aggregate the firm-level outcomes by sectors of activity between January 2004 and December 2011. There are 212 sectors: 92 in retail and 120 in wholesale. The sector panel has 20,352 monthly observations.

Reported Revenue: The NFP program aims to ensure that firms accurately report final sales. Accordingly, the gross revenue reported by a firm is the key variable directly affected by NFP. In addition, all firms must report their gross revenue to the tax authority on a monthly basis. Other outcomes such as tax liabilities and reported inputs require sample restrictions as described below. Therefore, this variable is the primary outcome in my empirical analysis of firm compliance. For more details on the specific forms used to construct this variable, see online Appendix B. Table 1 describes the firm sample. Statistics for the firm sample include the monthly gross reported revenue by firm for the key groups I use in the empirical analysis.

\footnotetext{
${ }^{44}$ Due to confidentiality reasons, I do not have access to data on audits rate or any information uncovered from audits. In addition, the data were de-identified, and no establishment data were provided from sectors that have fewer than five establishments, or from sectors in which one establishment is responsible for over 90 percent of the sector's tax revenue of that sector. In the groups of sectors I analyze, retail and wholesale, 126 establishments were excluded from a total of 1,035,933 establishments registered in São Paulo over the period of analysis.

${ }^{45}$ All the results are robust to using establishments as the unit of analysis instead. In São Paulo, 94.08 percent of firms are a single establishment, and the average number of establishments per firm is 1.18.
} 
TABle 1 -Descriptive Statistics

\begin{tabular}{|c|c|c|c|c|}
\hline & Observations & Mean & SD & Time period \\
\hline \multicolumn{5}{|l|}{ Firm sample } \\
\hline \multicolumn{5}{|l|}{ Retail firms } \\
\hline Reported revenue & $37,717,931$ & $18,209.68$ & 459,832 & Jan.2004-Dec.2011 \\
\hline Number of receipts with SSN & $12,838,202$ & 174.30 & 12,925 & Jan.2009-Dec.2011 \\
\hline Number of consumers & $12,838,202$ & 106.18 & 7,047 & Jan.2009-Dec.2011 \\
\hline \multicolumn{5}{|l|}{ Wholesale firms } \\
\hline Reported revenue & $3,494,539$ & $95,147.40$ & 384,970 & Jan.2004-Dec.2011 \\
\hline \multicolumn{5}{|l|}{ Consumer sample } \\
\hline Number of receipts & $181,032,084$ & 8.75 & 9.23 & Jan.2009-Dec.2011 \\
\hline Number of businesses & $181,032,084$ & 5.24 & 5.16 & Jan.2009-Dec.2011 \\
\hline Tax rebate & $181,032,084$ & 4.66 & 8.18 & Jan.2009-Dec.2011 \\
\hline Total expenditure in SSN receipts & $181,032,084$ & 502.89 & $1,060.49$ & Jan.2009-Dec.2011 \\
\hline Number of lottery tickets & $181,032,084$ & 1.40 & 4.86 & Jan.2009-Dec.2011 \\
\hline Lottery prize value & $181,032,084$ & 0.57 & 3.33 & Jan.2009-Dec.2011 \\
\hline
\end{tabular}

Notes: Table 1 presents descriptive statistics of the main variables for each data source: firms and consumers. All values are in US dollars (US\$1 $=\mathrm{R} \$ 2$ ) and are measured monthly. Reported revenue is the monthly gross reported revenue by firms. Number of receipts with SSN is the monthly number of receipts firms report to the tax authority with the Social Security Numbers (SSNs) of the consumer. Number of consumers is the total number of different SSNs to which firms issue a receipt. The consumer sample includes consumers that participate in at least one lottery between June 2009 and June 2011. Number of receipts is the total number of SSN receipts a consumer gets per month. Number of businesses is the number of different establishments for which a consumer gets SSN receipts per month. Tax rebate is the total tax rebate consumers get from the SSN receipts. Total expenditures in SSN receipts is the total amount of money (US\$) spent with SSN receipts. Number of lottery tickets is the total number of lottery tickets a consumer holds per month. Lottery prize values is the total amount (US\$) of lottery prizes per month. All variables in the consumer sample are assigned a zero when missing for a given time period. For details on the sample and data construction, see Section II and online Appendix B.

Tax Liabilities: It is possible that firms' tax liabilities do not respond to the policy in the same way as reported revenue as it also depends on reported inputs. The data available to this study, however, have some limitations to look at tax liabilities by firms. The variable I observe in the data is the amount of tax a firm is due to remit to the tax authority, not their tax liability. There could be substantial differences between these two quantities. An important driver of this difference is tax withholding within the VAT chain: part of the tax that is due by a firm is withheld and remitted by a upstream or downstream trade partner. This measurement problem introduces mechanical drops and increases in tax liabilities by firms that are difficult to control for as withholding rules are based on products and I do not observe products. Yet, there are some sectors that are less affected by withholding than others. Therefore, in order to look at tax liabilities, I restrict attention to the subset of firms (henceforth, tax sample) that are in sectors with little tax withholding throughout the period of analysis such that the tax due I observe best approximates the tax liabilities of firms. ${ }^{46}$

\footnotetext{
${ }^{46}$ To identify sectors less affected by withholding I proceed as follows: for firms in the VAT, which submit more detailed tax returns, I obtained an aggregation of the total values of input and output transactions that are in tax codes related to withholding. I aggregate these firms by sector, and calculate how much of total inputs and sales transactions are affected by withholding during the period of analysis. Then I restrict attention to sectors for which neither the input or output transactions affected by withholding represent more than 1 percent of the total input or output reported by VAT firms in those sectors. Further details on tax liability measurement can be found in online Appendix B.
} 
Reported Inputs and Value Added: For firms registered in the VAT (as opposed to the turnover tax regime described in Section II), the tax returns include reported inputs. In order to understand the change in tax liabilities, it is helpful to analyze changes in expenses claimed and the resulting value added. For this analysis I restrict attention to firms that are registered as VAT throughout the period of analysis in order to be able to observe changes in reported expenses. This sample restriction is important as firms that switch in and out of the VAT will have gaps in their reported expenses due to the tax form they have to file.

Because the impact on tax liabilities, reported inputs, and value added use subsets of firms, I show the effects on reported revenue for these samples to allow for a direct comparison with the overall sample.

Receipts: The micro-data on receipts capture purchases by consumers between January 2009 and December 2011. For these receipts the data include: month and year it was issued, the total amount spent, and an establishment identifier. Therefore, starting in January 2009, I can calculate by firm how many receipts have a SSN on them and the total value of these receipts. The micro-data with receipts detail linking individual to firms before January 2009 were not available to this study.

Complaints: Thirteen million individuals created an online account at the tax authority's website from October 2007 to December 2011. From these accounts, it is possible to observe the time and quantity of complaints filed against specific establishments. The whistle-blower analysis in Section IVA uses data on the timing of when a firm received its first complaint.

In order to reduce the influence of outliers, I winsorize the firms' outcomes by their ninety-ninth percentile value using the monthly micro-data panel, i.e., I replace all values above the ninety-ninth percentile of the reported revenue distribution by the ninety-ninth cutoff percentile value. Online Appendix A shows results using alternative top coding thresholds.

Consumer Data.-Consumer-level datasets are based on de-identified administrative data from NFP receipts and from online account activity at the tax authority's website. ${ }^{47}$ Importantly, the consumer-level data was generated by the NFP program. Therefore, there is no "pre-NFP" data on receipts, or any other individual characteristic. ${ }^{48}$ Further details on data sources and measurement can be found in online Appendix B.

Receipts: As described above, the receipts data file captures purchases for which final consumers asked for SSN receipts between January 2009 and December 2011. The main variables I derive from the receipts dataset are (i) number of receipts: the total number of SSN-identified receipts that a consumer asks for per month;

\footnotetext{
${ }^{47}$ For confidentiality reasons, no information that may identify individuals was available to this study. A "scrambled" unique identifier was created for each individual SSN, and no information on names or addresses was provided. Also, for a given receipt, the total amount spent is rounded to the nearest integer, and the final data contain no information on prices or products that were purchased.

${ }^{48}$ The state tax authority has no information on individual income tax records or any other federal tax data. Apart from motor vehicle property information, state tax authorities do not usually collect data on individuals.
} 
(ii) total expenditures with a SSN: the total amount of money spent associated with the SSN-identified receipts, aggregated by consumer, per month. In order to reduce the influence of outliers, I winsorize the number of receipts and total expenditure in $S S N$ receipts by their ninety-ninth percentile value using monthly micro-data.

Lotteries: From consumers' online accounts, it is possible to observe the receipts they ask for, their participation in lotteries and the value of cash prizes. ${ }^{49}$ The main variables derived from the online account dataset are (i) number of lottery tickets: the total number of lottery tickets a consumer holds per month; (ii) and lottery prizes: the number of lottery prizes and the value of lottery prizes per month. I restrict attention to 24 lottery draws between July 2009 and June 2011, i.e., 6 months before and after the first and last lottery available for this analysis.

Consumer Sample: I restrict attention to 5,028,669 consumers who participated in the lotteries between July 2009 and June 2011. This number includes lottery winners and a 10 percent random sample of non-winners in each lottery draw. The second panel of Table 1 displays the descriptive statistics for these consumers. All the variables are "unconditional," i.e., the number of lottery tickets, prizes and rebates consider the entire period that consumers could be asking for receipts and participating in lotteries, so these variables take value 0 when consumers do not ask for receipts or are not registered yet to participate in the lotteries.

\section{The Effect of Third-Party Information Trails on Firm Compliance}

To investigate the degree to which the availability of third-party information trails introduced by consumer rewards for requesting receipts can improve firm compliance, I begin by exploiting the impact of the introduction of the NFP program on revenue reported by firms using a difference-in-differences (DD) research design. I focus here on firms' reported revenue as it is the margin directly affected by the policy.

The identification strategy exploits variation in treatment intensity from the policy change. I compare two downstream sectors affected differently by the consumer monitoring program: retail and wholesale. NFP targets final consumer sales, so firms that sell mostly to final consumers are more affected than firms selling mostly to other firms. To exploit this difference I compare "treated" retail sectors to "control" wholesale sectors. I use a DD design to estimate changes in reported revenue by firms in each group before and after the implementation of the program.

Figure 1 shows descriptive statistics to motivate the comparison between retail and wholesale. Even though the NFP program is targeted at final consumer sales, consumers who purchased directly from wholesalers and manufacturers could enjoy the same reward benefits as in retail purchases. Panel A of Figure 1 shows the total number of receipts with a consumer's SSN in each group of sectors. The receipt-level data available to this study start in January 2009 only, but they clearly

\footnotetext{
${ }^{49}$ All data on approximately 90 consumers who won one of the top 3 lottery prizes of over US\$500 were excluded from the datasets available to this study for confidentiality reasons. See online Appendix B for more details.
} 
Panel A. Total number of receipts with a SSN

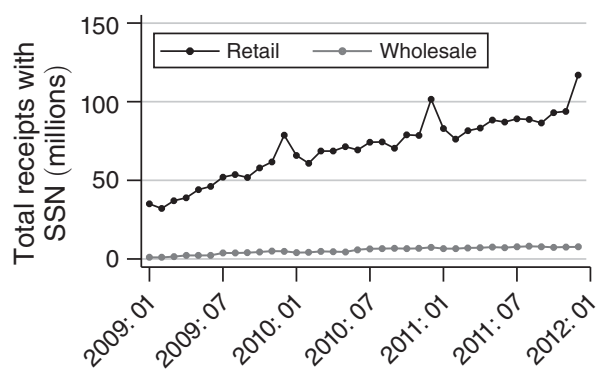

Panel B. Sare of reported revenue from SSN receipts

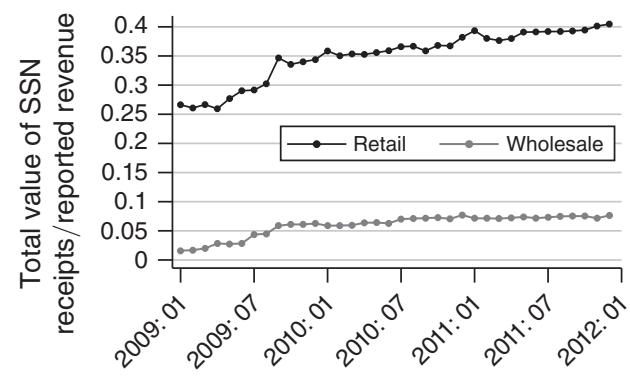

Figure 1. NFP Receipts and Revenue Shares: Retail versus Wholesale

Notes: Panel A shows the aggregate number of SSN receipts issued by firms in retail versus wholesale sectors. The figure plots the raw data. The spikes around December of each year follows the seasonal variation in consumption. Panel B shows the share of the total reported revenue in retail that is covered by SSN receipts in retail sectors and wholesale sectors. Even though the program was created in October 2007, the data from the NFP program available for the analysis begins in January 2009. For more details, see Section II and online Appendix B. The two figures provide support to the intensity of treatment variation if the difference-in-differences research design discussed in Section III. They show how Retail sectors were affected relatively more than the wholesale sectors by the NFP program, and that the take-up of the program gradually increased over time.

show a substantial difference in the magnitude of the number of receipts with SSN between the two groups of firms. Panel B of Figure 1 shows the share of revenue in each sector that is covered by SSN receipts. For retail sectors, this share reaches 40 percent in 2011 while it is always below 9 percent in wholesale sectors in the period of analysis. The trends in both panels also indicate that take-up of the policy increased over time, suggesting that the impact of the policy may also be gradual rather than a sharp change at the onset of the policy.

One advantage of the data is that I observe a long time series of pre-NFP observations of reported revenue changes in the sector groups. Thus, I can shed light on whether a key identification assumption in a DD holds: that trends in potential reported revenue changes are parallel for retail and wholesale sectors. Panel A of Figure 2 displays changes in total raw reported revenue by group of sectors from January 2004 to December 2011. In this figure, each data point is scaled by the average monthly reported revenue before the introduction of the NFP in October 2007 for the group.

In panel A of Figure 2, retail and wholesale reported revenue changes closely trace each other until program implementation. The vertical lines highlight the key moments in the implementation of the program discussed in Section IIB. Following implementation, change in reported revenue gradually increases in retail sectors, relative to wholesale sectors. Online Appendix Figure A2 shows that the firms in the excluded sectors upstream behaved similarly to wholesale, which is consistent with the argument that firms that do more business to business transactions should be affected less by this policy. The gradual change in panel A of Figure 2 is consistent with the fact that the program was not implemented at once, and consumer participation increased steadily over time. Since the figure displays raw data, there is quite a bit of variation across months of the year due to the seasonality of consumption. In 


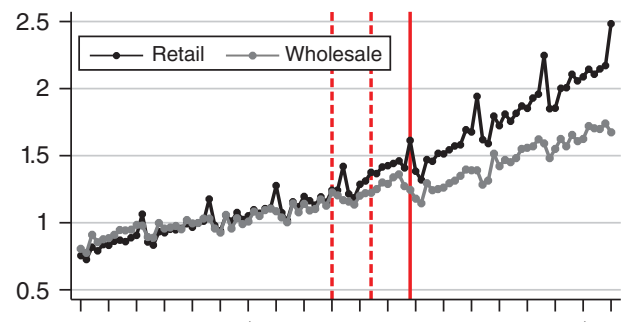

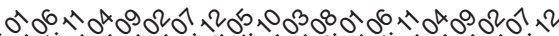

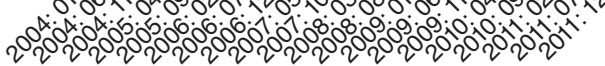

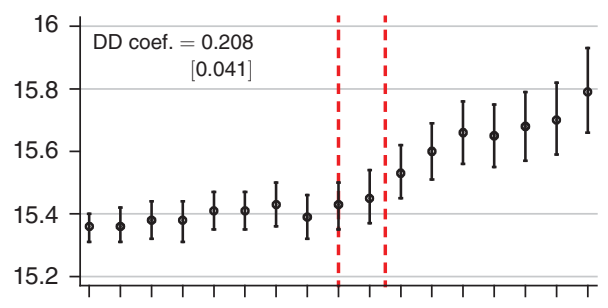

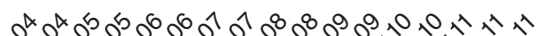

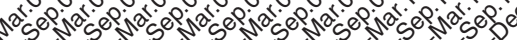

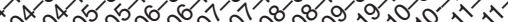

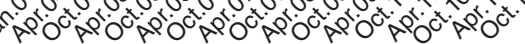

Figure 2. Effect of the Policy on Reported Revenue: Retail versus Wholesale

Notes: Panel A shows reported revenue changes for retail and wholesale sectors. Each line is the revenue reported by all firms aggregated by retail or wholesale scaled by the average monthly reported revenue before October 2007 for each sector group. The figure plots the raw data. The are spikes around December of each year follows the seasonal variation in consumption. The vertical lines highlight the key dates for the implementation of the NFP program: phase-in of sectors begins in October 2007 and ends in May 2008, and the first lottery based on the purchases with SSN receipts was introduced in December 2008. Panel B plots regression coefficients from estimating specification (5) in Section III using a sample of 212 sectors between January 2004 and December 2011. The sector sample has 20,352 observations. The difference-in-differences (DD) coefficient displayed in the figure is estimated using the specification (6) in Section III where the DD variable is defined by the interaction between a dummy for retail sectors and a dummy that equals 1 for time periods after Ocobert 2007. Standard errors are clustered by sector. See online Appendix Figure A2 and panel B of Table A1 for robustness checks.

particular, in retail sectors, reported revenue spikes each December, consistent with increased holiday-related consumption.

In order to measure the effect of the program across time, I run a flexible DD specification that includes 17 time dummies for 6-month windows from 2004-2011, using October 2007 (the starting point of the program's implementation) as a reference point, and using data aggregated at the 7-digit level in a balanced panel. Each 6-month window, denoted by $k$, is associated with a dummy variable Period $_{t}^{k}$, which equals 1 if month $t$ falls within window $k: 50$

$$
\ln R_{s t}=\eta_{s}+\gamma_{t}+\sum_{k=-8}^{8} \beta^{k}\left(\text { Treat }_{s} \cdot \text { Period }_{t}^{k}\right)+u_{s t}
$$

where $\ln R_{s t}$ is the $\log$ of reported revenue in sector $s$ and time $t ; \eta_{s}$ are seven-digit sector fixed effects and $\gamma_{t}$ are dummies for each month of each year. The variable Treat $_{s}=1$ if sector $s$ is a retail sector, and $u_{s t}$ is clustered by sector. This specification allows me to show the treatment effect across time, while controlling for finely-defined time and sector effects.

Panel B of Figure 2 plots the coefficients and the 95 percent confidence intervals from estimating equation (5) without a constant. The difference between the two groups is relatively constant before NFP. By the time the program is fully implemented the difference in log reported revenue between the two groups begins to

\footnotetext{
${ }^{50}$ For instance, Period ${ }_{t}^{0}=1$ if $t \in\left[\right.$ October 07,March 08], Period ${ }_{t}^{-1}=1$ if $t \in[$ April 07,September 07], and Period ${ }_{t}^{1}=1$ if $t \in[$ April 08, September 08].
} 
grow. This effect, averaged across all post-implementation periods, can be estimated from a standard DD specification,

$$
\ln R_{s t}=\eta_{s}+\gamma_{t}+\text { BTreat }_{s} \cdot \text { Post }_{t}+u_{s t},
$$

where Post $_{t}=1$ if $t \geq$ October 2007 and $u_{s t}$ is clustered by sector. Panel B of Figure 2 displays the estimated DD coefficient $\hat{\beta}$ from estimating equation (6). The results suggest that the NFP program induced a positive and significant 21 percent increase in reported revenue by firms across the 4-year period following implementation. Because I am exploiting differences in the treatment intensity across firms, the estimated effect is likely a lower bound of the program's impact. The control group was also potentially affected by the policy: either directly from sales to final consumers or indirectly from the self-enforcing properties of the VAT.

In addition, I use the firm-level data to test whether the estimated DD effect in equation (6) is similar when controlling for firm $i$ fixed effects. The empirical strategy is analogous to the sector-level analysis

$$
\ln R_{i t s}=\eta_{i}+\gamma \text { Post }_{t}+\beta \text { Treat }_{t s} \cdot \text { Post }_{t}+\varepsilon_{i t s} \text {. }
$$

The firm-level regression is run in a two-period DD, for which the $t$ is collapsed by pre and post. The pre period is between January 2004 and September 2007, and the post period is between October 2007 and December 2011. This strategy avoids log of zero values in firms' monthly data, and helps address serial correlation issues when computing standard errors (Bertrand, Duflo, and Mullainathan 2004). The regressions are dollar-weighted, i.e., each observation is weighted by its pre-NFP value, such that each observation contributes to all regression estimates according to its economic scale to best approximate the sector aggregate-level analysis. The term $\ln R_{i t s}$ is the $\log$ of reported revenue where in firm $i$ in period $t$ and sector $s$. The error $\varepsilon_{i t s}$ is clustered by sector.

Column 1 of Table 2 shows the DD coefficient for the firm-level regression. It is comparable to the aggregate effect: a 25 percent increase in reported revenue for retail firms compared to wholesale firms. This increase in compliance is sizable, and shows that incentives to consumers can indeed change firm's ability to under-report sales. The implications of this increase in compliance for tax revenue, however, are not obvious. There are two separate issues: (i) such an increase in reported revenue may not generate a similar increase in tax revenue depending on how reported inputs are adjusted, and (ii) the net increase in taxes can be lower as the government is forgoing tax revenue through rewards. Section V discusses these two points in detail.

I conduct a number of robustness checks for both the sector and firm-level regressions reported in online Appendix Table A1. The results are robust to winsorizing the top 5 percent or the top 0.1 percent to deal with the influence of outliers, and for clustering standard errors by firm instead of sector in the firm-level estimation. In addition, in online Appendix Figure A3 I investigate whether the retail-wholesale comparison is indeed capturing an increase in compliance from the NFP policy, rather than an increase in actual revenue or a nationwide change in trends across the two groups of sectors. Based on aggregate numbers from the tertiary sector annual 
TAble 2-Reported Revenue Effect: Retail versus Wholesale

\begin{tabular}{|c|c|c|c|c|c|}
\hline & \multicolumn{5}{|c|}{$\log$ reported revenue } \\
\hline & (1) & $(2)$ & (3) & (4) & (5) \\
\hline DD $($ Post October $07 \times$ retail $)$ & $\begin{array}{c}0.254 \\
{[0.0722]}\end{array}$ & & & & \\
\hline $\mathrm{DD} \times$ large firms & & $\begin{array}{l}0.253 \\
{[0.0732]}\end{array}$ & & & \\
\hline $\mathrm{DD} \times$ small firms & & $\begin{array}{l}0.350 \\
{[0.0511]}\end{array}$ & & & \\
\hline $\mathrm{DD} \times$ high volume of different consumers & & & $\begin{array}{l}0.246 \\
{[0.0705]}\end{array}$ & & \\
\hline $\mathrm{DD} \times$ low volume of different consumers & & & $\begin{array}{c}0.0329 \\
{[0.0919]}\end{array}$ & & \\
\hline $\mathrm{DD} \times$ high volume of transactions & & & & $\begin{array}{c}0.253 \\
{[0.0335]}\end{array}$ & \\
\hline $\mathrm{DD} \times$ low volume of transactions & & & & $\begin{array}{c}0.018 \\
{[0.0391]}\end{array}$ & \\
\hline $\mathrm{DD} \times$ high value of transactions & & & & & $\begin{array}{c}0.097 \\
{[0.0689]}\end{array}$ \\
\hline $\mathrm{DD} \times$ low value of transactions & & & & & $\begin{array}{l}0.285 \\
{[0.0754]}\end{array}$ \\
\hline 3 rd-order polynomial of firm size $\times$ DD & & & $\mathrm{X}$ & $\mathrm{X}$ & $\mathrm{X}$ \\
\hline Time fixed effects & $X$ & $\mathrm{X}$ & $\mathrm{X}$ & $X$ & $\mathrm{X}$ \\
\hline Firm fixed effects & $\mathrm{X}$ & $X$ & $\mathrm{X}$ & $\mathrm{X}$ & $X$ \\
\hline Observations & $1,035,268$ & $1,035,268$ & $1,035,268$ & $1,035,268$ & $1,035,268$ \\
\hline Adjusted $R^{2}$ & 0.907 & 0.907 & 0.908 & 0.909 & 0.908 \\
\hline
\end{tabular}

Notes: Table 2 displays the main coecients from firm regressions. The variable $D D$ is defined as the interaction between a dummy for retail sectors (retail) and a dummy that equals 1 for time periods after October 2007 (Post October 07). The dependent variable is log of reported revenue by firm, and the data is collapsed into two periods: before and after October 2007. Time and firm fixed effects are included in all regressions. The regressions are dollar-weighted (each observation is weighted by the pre-policy reported revenue) such that each observation contributes to all regression estimates according to its economic scale to best approximate the aggregate effect. Column 1 shows the average DD estimate discussed in Section III. Columns 2 to 5 are discussed in Section IV. Column 2 splits firms in two groups: firms below the median of the baseline firm size distribution (Small firms) and firms above the median (Large firms). Column 3 splits retail sectors into two groups: sectors below the median volume of consumers across sectors (Low volume of different consumers) and sectors above the median of volume of consumers (High volume of different consumers). Volume of different consumers is defined the average number of different SSNs reported in receipts by firms in a given sector between 2009 and 2011. Column 4 splits retail sectors into two groups: sectors below the median volume of transactions distribution across sectors (Low volume of receipts) and sectors above the median of volume of transactions (High volume of receipts). Volume of receipts is defined by the average number of transaction by firms in a given sector between 2009 and 2011 . Column 5 aims to capture a similar variation as in column 4 , but it split retail sectors into two groups based on whether they are in sectors where transaction values are below the median transaction value across sectors (Low value of transactions) or above the median transaction value (High value of transactions). Transaction value is defined by the median transaction by firms in a given sector between 2009 and 2011. In order to control for firm size effects, the regressions in columns 3-5 include a third-order polynomial interacted with the DD variable. Size is defined by the average reported revenue by firms during a four-year period before program implementation. Standard errors are clustered at the sector level. See online Appendix Table A2 for robustness checks.

\section{survey, ${ }^{51}$ the difference between retail and wholesale revenue is constant across time in Brazil, so there does not seem to be a nationwide differential change in}

${ }^{51}$ PAC (Pesquisa anual do comércio) from the Brazilian Census Bureau (IBGE) is an annual national survey conducted by IBGE based on a sample of formal firms in Brazil. The information reported to the survey can more-accurately capture real economic activity as the survey data is highly confidential, and cannot be used to cross check information submitted to the government by firms. 
revenue between the two groups. ${ }^{52}$ Moreover, there is no such differential change in revenue for São Paulo firms in the survey data, which suggests that the effect observed in the tax data is indeed a reporting effect and not a real change in economic activity.

\section{Mechanisms: Whistle-Blower Threats and Collusion Costs}

In order to investigate the mechanisms through which a consumer reward policy can improve compliance, I turn to the micro-data on firms, receipts, and consumers following the predictions from the conceptual framework in Section I. First, I study the role of whistle-blower threats by examining heterogeneous effects of the program, and by analyzing the behavior of firms after consumers blow the whistle. Second, I investigate the role of collusion costs. I discuss heterogeneous effects of the policy that could be linked to fixed costs from frictions in setting a collusive deal, and I analyze behavioral biases with respect to reward value that may amplify individual responses to rewards, making it more costly for firms to match the government incentives.

\section{A. Whistle-Blowers}

Heterogeneous Effects.-I examine heterogeneity in the responses of firms to the NFP policy in order to shed light on how the government can credibly harness the information consumers have on firms' evasion to improve compliance. I begin by allowing the coefficient in specification (7) to be heterogeneous depending on the firm size distribution before the program. The sheer size of a firm could deter under-reporting even absent of incentives to consumers since the number of third-parties firms interact with can have a monitoring effect as discussed in Section I. Column 2 of Table 2 shows the DD coefficients separately for firms above (large firms) and below (small firms) the median firm size as measured by the pre-program reported revenue. The results are in line with the idea that the program affected more small firms that were likely evading more in the baseline.

Then, I use the number of different consumers a firm typically faces in their sector of activity to capture the increased detection probability under consumer monitoring: the larger the number of consumers the more likely it may be that one of those consumers will blow the whistle when the firm evades taxes. To construct this measure, I need to use data from the program, i.e., after implementation. In order to avoid using firm-level information that may reflect the treatment effect, I use sector level variation. To define the number of different consumers I count the number of different unique SSNs per firm from the receipts data, and I rank retail sectors by the average number of unique SSNs per firm. I take this source of variation to the data using the following specification:

$$
\ln R_{i t s}=\eta_{i}+\gamma \text { Post }_{t}+\sum_{m=1}^{2} \alpha_{m}\left(d_{m s} \cdot D D_{t s}\right)+f\left(x_{i}\right) \cdot D D_{t s}+\varepsilon_{i t s} .
$$

\footnotetext{
${ }^{52}$ The time period post-NFP overlaps with the Great Recession in the United States. The Brazilian economy, however, was not as affected by this particular financial crisis during the period of analysis, and the survey data do not suggest heterogeneous effects across the two groups of sectors.
} 
As in specification (7), I run this regression as a two-period DD, for which the data is collapsed by pre and post. Firm fixed effects are denoted by $\eta_{i}$. The term $f\left(x_{i}\right)$ is a third-order polynomial of firm size as measured by the average reported revenue three years before the program, and $D D_{t s}$ variable is the interaction between a dummy for retail sectors and a dummy that equals 1 for post October 2007. The error $\varepsilon_{i t s}$ is clustered by sector. The dummy $d_{1 s}=1$ if sector $s$ is below the median of the number of different consumers distribution across sectors, and $d_{2 s}=1$ if sector $s$ is above the median. I flexibly control for firm size effect through an interaction of $D D_{t s}$ with $f\left(x_{i}\right)$ to separate the overall size effect discussed above from the effect of number of different consumers as discussed in the conceptual framework. 53

Column 3 of Table 2 shows that the effect is concentrated among firms that face a high number of different consumers. This program is changing the availability of information trails, and the threat imposed by potential whistle-blowers might help to explain how this program can work despite collusion opportunities between the buyer and the seller.

Whistle-Blower Event Study.-The evidence above indicates that whistle-blower threats could be an important device to improve compliance. In order to further examine the effect of whistle-blowers, I exploit a direct link between the participation of consumers in the enforcement effort and firm behavior. I use a dataset with over 1 million complaints to analyze how firms respond after a consumer blows the whistle. It is worth noting, though, that there does not need to be a link between the number of complaints and the size of the effect of the policy in equilibrium. For instance, in an extreme case that the policy shifts all firms to full compliance, no complaints would be observed in the data.

The degree to which a firm responds to a consumer blowing the whistle depends on their beliefs. If firms believe that the probability $\varepsilon$ from Section I that a consumer will blow the whistle is too low, perhaps because they have never seen a consumer blow the whistle, they perceive $\varepsilon$ as being lower than it actually is. If this is the case, once firms observe consumers blowing the whistle for the first time, they may update upward their beliefs about $\varepsilon$, which increases compliance. Note that the beliefs do not have to be biased in a specific direction at baseline, just that some firms have beliefs that are too high and some others that are too low. Firms with beliefs that are too high may only learn very slowly (or even never) about the true probability because they will mostly comply. Firms with beliefs that are too low will learn more quickly about the true probability because at the beginning they may not comply as a result and will likely receive complaints. Therefore, it is possible that, on average, firms will update their beliefs upward after a first complaint, and thus increase compliance.

In the data, every month, a firm may receive a complaint from a consumer through the NFP website. A firm is typically notified by a complaint up to one month after it is submitted by the consumer. In order to study the effect of consumers' complaints

\footnotetext{
${ }^{53}$ These results are robust to winsorizing the dependent variable at different cutoffs $(0.1$ percent and 5 percent instead of 1 percent). Standard errors are also robust to clustering at the firm or time level instead of sector. See online Appendix Table A2. Similarly to the average effect, the heterogeneous results are assumed to share a common trend with the overall sample of wholesalers conditional on heterogeneous effects by firm size.
} 
I examine the impact of the first complaint a firm gets from a consumer through the website. Different firms received their first complaints at different points in time, and I can exploit the timing of the first complaint to assess the response of firms. The likelihood of receiving a complaint in a given point in time, however, may be driven by the volume of sales leading up to the first complaint. Moreover, it is possible that firms that have a large volume of sales in a given month may be followed by a lower reported revenue in the next period due to mean reversion or other seasonal characteristics. Therefore, exploiting the timing of the complaint alone might not be ideal, as subsequent changes in reporting patterns after the first complaint might reflect real changes in economic activity of the firm.

In order to circumvent mean-reversion and other seasonal effects, I build a counterfactual for each complaint event. I create an "event-control" group composed of firms that did not receive their first complaints by a given event date. That is, these firms may have received complaints after event time zero, but not before or at event time zero. I use a subset of the firm sample defined in Section IIC. I consider only retail firms, and within retail I only retain the firms that did not exit before 2009 . I use complaints that were filed between July 2009 and June 2011. Throughout this period, 134,054 or 25 percent of establishments received at least one complaint. Online Appendix B has more details about the samples.

For each firm, I consider the first complaint event as the first time any of its establishments received a complaint. I use a reweighting method based on quartiles of the propensity score of getting a complaint in a given period to control for firm characteristics and past outcomes. For a detailed description of the propensity score and reweighting, see online Appendix B. ${ }^{54}$

Let $i \in\{T, C\}$ index each firm as "complaint" $T$ or a "no-complaint" $C$ in a given month. Let $t_{o}$ index the month in which an outcome is observed, and $t_{e}$ index the month in which a consumer blows the whistle on the firm for the first time (the "event-month"). Define $k \equiv t_{o}-t_{e}$ as the number of "periods" or months after/ before the first complaint. I performed this reweighting exercise separately for each month between July 2009 and June 2011, and I collapsed the data by event-month $k \in[-6,6]$ using the propensity score weights for Figure 3.

Panel A of Figure 3 displays the number of receipts complaint and no-complaint firms report to the tax authority, and panel B shows changes in reported revenue relative to 6 months before the first consumer blows the whistle. The $x$-axis shows the distance in months $k$ to the first complaint or "event-month." The graph also displays the estimated DD coefficient from estimating the following equation in the micro-data:

$$
\ln Y_{i e k t}=\gamma_{i e}+\pi_{t}+\phi_{k}+\beta \cdot I_{i e k t}\{k \geq 0, i e=T\}+u_{i e k t},
$$

where $\ln Y_{i e k t}$ is either the $\log$ of the number of receipts or the $\log$ of reported revenue that firm $i$ reports to the government in calendar month of event $e$. The event-month

\footnotetext{
${ }^{54}$ The propensity score of a firm receiving its first complaint at a given time is estimated for each complaint date using age of the firm, number of establishments by firm, dummies for legal nature of the firm, sector fixed effects, dummy for location in the metropolitan region of São Paulo, and the three lags of third-order polynomials of reported revenue, reported receipts, SSN receipts and number of consumers.
} 
Panel A. Changes in the number of receipts

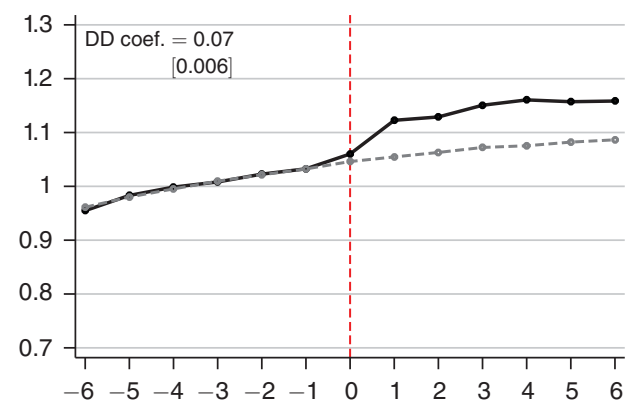

Panel B. Changes in reported revenue

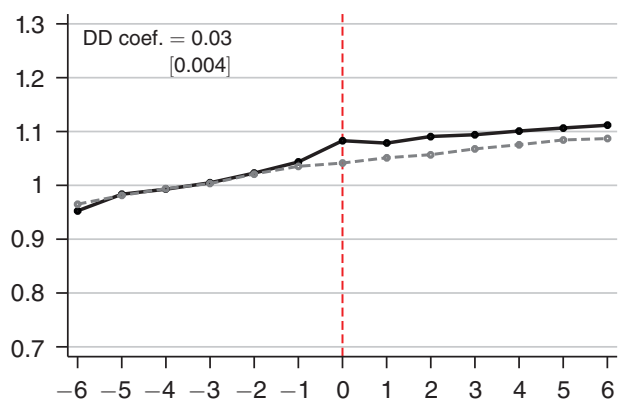

Figure 3. Whistle-Blower Effect on Firm Compliance

Notes: Panels A and B plot the changes in the total raw number of receipts firms issue and changes in reported revenue to the government before and after a firm receives the first complaint. Both graphs display changes across event-time where each data point is scaled by the outcomes average before the first complaint (event-time zero). The Complaint group is composed of firms that received their first complaint at event-time zero. The No complaint group is composed of firms that did not receive their first complaint at event-time zero and firms that did not receive a complaint until December 2011. The outcome is averaged across groups and event times using weights based on quartiles of the propensity score to get the first complaint in a given calendar time. The propensity score is estimated using age of the firm, number of establishments by firm, dummies for legal nature of the firm, sector fixed effects, dummy for location in the metropolitan region of São Paulo, and the three lags of third-order polynomials of reported revenue, reported receipts, SSN receipts and number of consumers (see online Appendix B for more details). The estimated DD coefficient displayed in each graph is based on estimating specification (9) described in Section IV using the micro-data and clustering the standard errors by the calendar date of the first complaint.

is indexed by $k$ and calendar date is indexed by $t$. I control for calendar time fixed effects $\pi_{t}$, event-month fixed effects $\phi_{k}$ and for firm-event fixed effects $\gamma_{i e}$. The same firm $i$ can be in $T$ or $C$ depending on the event as the control group draws from firms that did not yet receive a complaint by event $e$. Therefore, I can control for firm-event fixed effects to make sure I am only using variation within firm and event. Figure 3 displays the estimated DD coefficient $\hat{\beta}$ from estimating equation (9) for a window $k \in[-6,6]$ around each event. Standard errors are clustered by event $e$ and are robust to clustering by firm or by firm-event.

I find a significant 7 percent increase in the number of receipts firms issue and a significant 3 percent increase in reported revenue after firms receive their first complaint. The impact of the first complaint is capturing the overall impact of receiving complaints, as some firms received additional complaints after time zero. It can be interpreted as an increase in the perceived detection probability as firms learn that consumers can indeed share information with the government about their noncompliance. Audit probabilities could change as a result, but even if audit rates do not change, firms could perceive a higher risk of getting caught as the government is better informed. Note that it should be expected that this whistle-blower effect is smaller than the overall effect in the aggregate analysis because firms have likely already increased compliance prior to any complaint, in anticipation of the risk that consumers will blow the whistle if they do not change compliance at all.

Together, the impact of consumers blowing the whistle and the heterogeneous effect of the consumer-monitoring is consistent with the argument that 
whistle-blowers can be an important part of the explanation for why third-party reporting is so effective to ensure compliance. In the context of NFP, it can be a tool for the government to tap into the wealth of information that consumers elicit when asking for receipts from hard-to-tax firms that self-report final sales.

In the case of NFP, 1 percent of consumers filed complaints about 20 percent of firms. This is not necessarily surprising as the number of consumers is much larger than the number of firms, but it highlights how this diffuse monitoring mechanism can improve enforcement even when most consumers are not willing to actively participate in complaints. Arguably firms do not know which consumers among many who are asking for receipts are willing to be whistle-blowers, so the government can exploit this information asymmetry to generate a deterrence effect from this diffuse monitoring.

\section{B. Collusion Costs}

As discussed in the conceptual framework, collusion can be costly above and beyond the additional risk of getting caught from whistle-blower threats. First, if there are any frictions in setting a collusive deal, there could be a fixed cost per transaction that is being concealed. Second, the more consumers value rewards, the more firms need to compensate consumers in a collusive deal through discounts, which decreases the returns from evasion. In this subsection, I discuss heterogeneous results of the policy on firms that may face different collusion costs. Then, I provide evidence on consumer's responses to the lottery rewards. I show that the program is salient by exploiting variation in the disbursement schedules of the monetary rewards. Then, I exploit variation from the monthly lotteries to investigate whether potential behavioral biases with respect to lotteries may amplify the response consumers have from rewards.

Fixed Costs of Collusion.-The comparative statics discussion of Section I distinguishes between the number of consumers (that should affect whistle-blower threats as discussed above), and the number of transactions or value of transactions (that should affect the cost of evasion for a given firm size). In order to shed light on this channel, I analyze heterogeneous responses to the policy by volume of transactions and the receipt value. To construct these measures, I follow the same logic as in the number of different consumers described above. To define the volume of transactions I rank sectors based on the count of the average number of receipts per firm in retail. To define receipt value I calculate the median receipts per firm in retail and then I use the median value by sector to rank retailers.

Columns 4 and 5 of Table 2 show the results using specification (8) and dummies for sectors above and below the median volume of transactions and receipt value, respectively. The effect of the program is stronger for firms in sectors with high "foot-traffic," firms in sectors that have a high volume of transactions and small ticket items are affected more controlling for differential effects by firm size. These results are consistent with collusion costs being part of the mechanism through which third-party information can affect compliance. Although there is room for collusion, the policy can introduce a concealment cost that disproportionally affects firms that must collude multiple times to continue evading. 
The heterogeneous effects by number of different consumers, volume of transactions, and receipt value are picking up similar variation in the data, and it is difficult to identify the relative importance of each channel. Still, these patterns help shed light on the different mechanisms though which this policy can operate. These mechanisms could be related: the concealment costs are arguably due to the secretive nature of collusion that is, arguably, a consequence of whistle-blowers concerns. If firms could openly announce clear discount policies to consumers, these fixed costs would be mitigated but they would run a higher risk of getting caught.

Consumers Responses to Rewards.-Now, I turn to the value of rewards to investigate how consumer behavior may contribute to the impact of the policy.

Are Consumers Paying Attention to the Rewards? I verify that the release of monthly lottery results is salient to consumers by examining changes in the volume of Google searches about NFP. Google data aggregate information from millions of searches, and they can meaningfully capture salient social patterns that other survey methods cannot capture as easily (Stephens-Davidowitz 2014) ${ }^{55}$ Around the fifteenth of each month, the tax authority performs the lottery draws and releases information on lottery winners. A consumer can only check her lottery results by logging in to her online account at the tax authority's website. The actual address is not straightforward to remember (http://www.nfp.fazenda.sp.gov.br); as a result, consumers looking for this address may search for the program's name or initials.

Panel A of Figure 4 pools Google search data from the first to the last day of each month between 2008-2011, and it scales each data point by the first day of the month. ${ }^{56}$ From the figure, it is clear that there is an increase in search volume around the fifteenth of the month the tax authority releases the results of the lotteries: it is 16 percent higher than on the first day of the month. The gray line displays data from searches with the word "futebol" (soccer in Portuguese) which provides a metric of how the general volume of Google searches varies within a month. Panel B shows that the timing of disbursement is also salient: the total amount of rewards requested for bank account deposits spike as soon as tax rebates become available every April and October. ${ }^{57}$

The Lottery Effect: I exploit variation from the monthly lotteries to investigate whether potential behavioral biases with respect to lotteries may amplify the response consumers have from rewards. As detailed in Section 1, the more consumers value the rewards $\kappa(\alpha)$, the more effective NFP will be in preventing tax evasion for a given reward $\alpha$. The lottery component of the rewards may leverage consumers' taste for gambling or individual behavioral biases. Friedman and Savage (1948) noted that many governments consider lotteries an effective way to raise revenue

\footnotetext{
${ }^{55}$ Hoopes, Reck, and Slemrod (2015) use Google and Wikipedia searches about US income tax to show that the propensity to search varies systematically with tax salience.

${ }^{56}$ I exclude the months of April and October, during which the government disburses the tax rebates, to make sure that the search pattern is related to the lotteries.

${ }^{57}$ As described in the previous section, the tax authority disburses tax rebates biannually. Consumers can use rewards in other ways, e.g., they can be transferred to a third party, used to pay other taxes or saved for a later deposit, so the total amount in the graph will not necessarily add up to the total amount available to consumers at that point in time.
} 
Panel A. Timing of lottery results: Google searches for Nota Fiscal Paulista

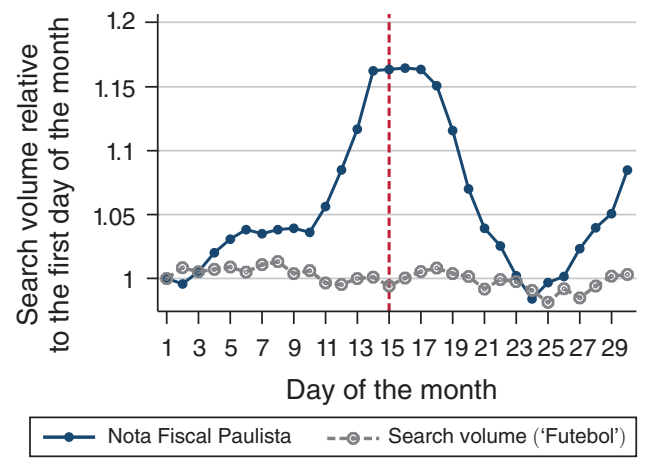

Panel B. Timing of tax rebate: rewards claimed by consumers

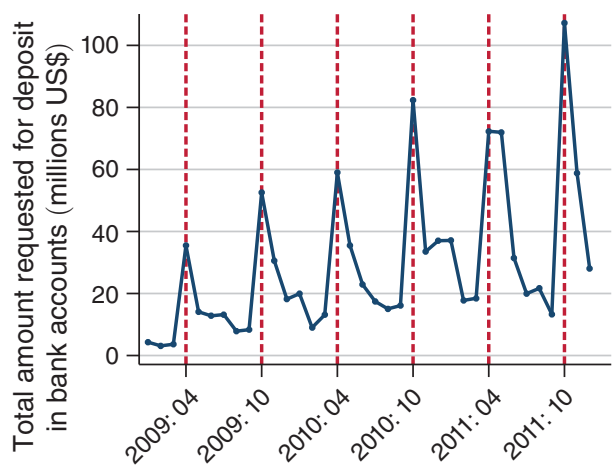

Figure 4. Are Consumers Paying Attention to the Rewards Schedule?

Notes: Panel A displays the search volume from Google Trends website for Google searches with terms related to "nfp" or "nota scal paulista" or "nota paulista" pooled by day of the month from IPs addresses in the state of São Paulo between 2008 and 2011. It also displays searches for "futebol" (soccer in Portuguese) pooled by day of the month from IPs addresses in the state of Sao Pãulo for the same time period. The lottery results are released around the 15 th of each month marked by the solid vertical line. As described in Section II, the tax authority does a biannual disbursement of the tax rebates: every April and October, and creates salience for the program at different dates within the month. Panel B shows the data for rewards claimed across time: each data point is the total amount in millions of US\$ requested for direct deposit in consumers bank accounts.

as individuals may be willing to pay for lotteries paying a negative expected value. Filiz-Ozbay et al. (2015) find evidence that prize-linked savings offered by commercial banks and governments around the world may be more effective at increasing savings than regular interest payments with the same expected value.

In addition, the NFP monthly lotteries typically have three very large prizes (the top prize can be as large as US\$500,000) and millions of small prizes, which is a payoff structure commonly seen in gambling games and prize-linked savings accounts (Guillén and Tschoegl 2002). The skewness of the prize values may be a tool to create salience. Bordalo, Gennaioli, and Shleifer (2013) argue that when comparing alternative risky lotteries, individuals pay attention to the payoffs that are most different relative to their objective probabilities. If consumers exhibit behavioral biases with respect to the NFP lotteries, it would be more difficult for firms to try and replicate the government's rewards to avoid truthfully reporting their sales.

In order to shed light on the role of behavioral effects, I exploit the random variation in lottery wins to document consumer participation responses to lottery rewards. Consumers may use past wins as a signal of their likelihood of getting a lottery prize, which would be consistent with misperception of randomness and the use of heuristics in making choices under uncertainty. Guryan and Kearney (2008) find that consumers increased their estimate of the probability that a ticket bought from the store that sold a winning ticket in the past would be a lottery winner (the "lucky store effect"). ${ }^{58}$ I restrict attention to small cash prize wins of 5 dollars to

\footnotetext{
${ }^{58}$ They argue that consumers may rationalize the observed streaks by inferring heterogeneity in the data generating process. In the context of financial investments, Kaustia and Knüpfer (2008) find evidence of reinforcement learning in investors' behavior: personally experienced outcomes are overweighted in future choices.
} 
investigate whether consumer participation increases after a lottery win. Because the value of the prize is small, a systematic change in behavior after a lottery win is arguably due to an increase in the perceived returns to participation in the program and not an income effect.

To analyze the effect of lotteries I create a natural "event-control" group composed of people that held the same number of lottery tickets in a given lottery but did not win prizes. I use the consumer sample defined in Section IIC. Let $i \in\{T, C\}$ index each consumer as "winners" $T$ or a "non-winners" $C$ in a given month. I use a reweighting method based on DiNardo, Fortin, and Lemieux (1996) to flexibly control for the number of lottery tickets individuals hold. I create bins for each possible number of lottery ticket holdings up to 40 tickets, which is the set of lottery tickets for which there is common support between the two groups. ${ }^{59}$ I then reweight the non-winners group such that each bin carries the same relative weight as the analogous bin in the winner group distribution across lottery ticket holdings. This method ensures that I use the random component of the lottery by matching the two groups based on the odds of winning prizes. 60

Let $t_{o}$ index the month in which an outcome is observed, and $t_{e}$ index the month in which the consumer wins the lottery (the "event-month"). Define $k \equiv t_{o}-t_{e}$ as the number of "periods" or months after/before the lottery win. I performed this reweighting exercise separately for each of the 24 lotteries of 5-dollar prizes. I then collapsed the data for each lottery by group and period $k \in[-3,6]$ using the DFL weights for Figure 5.

Panel A of Figure 5 displays the average number of receipts for which lottery winners and non-winners ask before and after winning a 5-dollar prize. The $x$-axis shows the distance in months to the lottery $k$. Each graph displays the estimated DD coefficient from estimating the following equation in the micro-data for $k \in$ $[-3,6]$ :

$$
y_{\text {jekt }}=\gamma_{j e}+\pi_{t}+\phi_{k}+\beta \cdot I_{j e k t}\{k \geq 0, j e=W i n\}+u_{j e k t},
$$

where $y_{j e k t}$ is the number of SSN receipts or the total value of receipts consumer $j$ asks for in "event-month" $k$ and calendar month $t$. I control for calendar time fixed effects $\pi_{t}$, event-month fixed effects $\phi_{k}$ and for consumer-lottery draw fixed effects $\gamma_{j e} \cdot{ }^{61}$ Standard errors are clustered by lottery draw, and are very similar if clustered by consumer.

Panel A of Figure 5 shows that there is a significant difference in consumer participation in the program between lottery winners and non-winners as measured by the number of receipts they ask for with their SSN. The evidence is consistent with a behavioral explanation, given that there is a significant 0.07 difference $(0.5$ percent

\footnotetext{
${ }^{59}$ Online Appendix Figure A5 shows an example of the distribution of lottery ticket holdings among winners and non-winners. It is clear that the winner group typically holds more lottery tickets. Since the number of lottery tickets is determined by consumers' participation, it is important to carefully control for the odds of winning.

${ }^{60}$ For a detailed description of a similar application of DFL-reweighting, see Yagan (2015). For more details on reweighting, see online Appendix B.

${ }^{61}$ The same consumer $j$ can be a winner and a non-winner depending on the lottery draw as the control group is composed by a 10 percent random sample of consumers that did not win a prize in lottery draw $e$, but could have won in another lottery draw. Therefore, I control for consumer-lottery draw fixed effects. See online Appendix B for more details on the sampling and reweighting.
} 
Panel A. Number of receipts

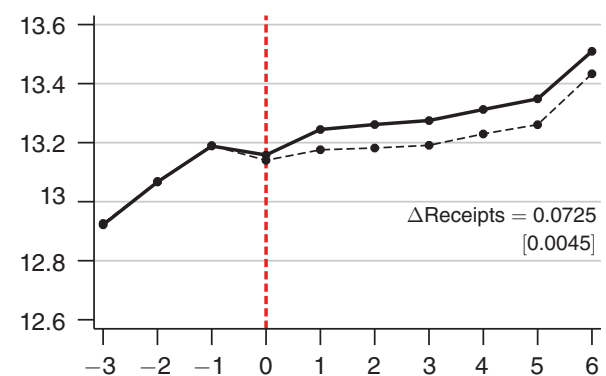

Panel B. Total value of receipts (US\$)

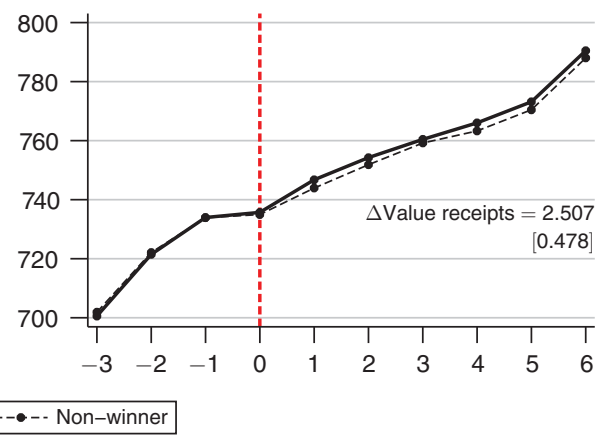

Figure 5. The Effect of a 5-Dollar Lottery Win on Consumer Participation

Notes: The graphs show the raw data by month aggregating all lotteries from June 2009 to June 2011. The $x$-axis is the number of months since the individual participated in a lottery. The winner group got a cash prize of US\$5 (R \$10) and the non-winner group did not get any prize. Panel A plots the total number of receipts consumers ask in each group before and after the lottery draw at event-time zero. Panel B shows the total value of receipts (in US\$) for each group before and after the lottery draw at event-time zero. Before taking the averages in each case, I create bins for each possible number of lottery ticket holdings from 1-40 tickets in each monthly lottery for 24 lotteries between June 2009 and June 2011. Then I reweight the non-winners group such that each bin carries the same relative weight as the winner group distribution across lottery ticket holdings (for more details, see online Appendix B). The DD coefficient displayed in each graph is based on estimating specification (10) in Section II using the micro-data and the lottery ticket weights. Standard errors are clustered by lottery draw.

increase) between the number of receipts lottery winners and non-winners ask for after winning a US\$5 prize, and the effect persists after at least 6 months. Since the odds of winning are independent of past wins, the change in behavior observed in panel A of Figure 5 suggests that lottery wins could be working as a nudge by making the odds of winning more salient and reinforcing the propensity to ask for receipts. Alternatively, consumers could be using the past lottery win as a signal of luck, and therefore perceive a higher expected return from participating in the program. 62

Panel B shows the effect of a $\$ 5$ win on the total value of receipts. There is a persistent increase of US\$2.5 on average in monthly expenditures after the lottery win. This increase is a change in behavior that lasts for at least 6 months after the lottery draw. If I run specification (10) in a collapsed data to observe the total expenditure before versus after the lottery win, there is a statistically significant increase in SSN receipts value of $\$ 16.14$ (SE 3.08) after winning US\$5. Therefore, the effect of the lottery win cannot be attributed to the cash prize alone.

An alternative explanation is that consumers use lottery wins as evidence that the program works as advertised. In online Appendix A, I study the effect of a US\$5 win for a sample of individuals that won the lottery once before, in which case the effect of confirming that the program works should not be as relevant. Another alternative

\footnotetext{
${ }^{62}$ Online Appendix Figure A7 shows the same picture for all prize levels. As the size of the lottery win grows, the estimated effect is larger. This pattern indicates that the change in behavior is indeed due to the lottery win. The effect, however, is confounded with the fact that larger prizes are more relevant cash shocks that can increase the level of overall consumption.
} 
explanation is that individuals that do not win the lottery get discouraged from the lottery loss. To try to control for this issue, I compare winners of $\$ 5$ prizes to $\$ 10$ prizes. The difference between the two groups is still a $\$ 5$ cash prize, but both won the lottery. In both comparisons I find a statistically significant difference in the number of receipts consumers ask for after the lottery win that represents a 0.4 percent change, which provides further support for the interpretation that a small cash prize can change winners' behavior through a higher perceived returns to participation in the program. The results are reported in panels A and B of online Appendix Figure A6.

The data do not allow to tease out the exact behavioral bias that the government is exploiting, but the evidence suggests that the lottery component can be a relevant mechanism to explain how NFP can generate enough consumer participation to improve enforcement. Lotteries are used in other contexts such as lottery-linked savings accounts offered by commercial banks, possibility exploiting similar biases. Also, if people misperceive probabilities or simply have a taste for playing lotteries, it would be more costly for firms to match government's incentives. Not only could it increase the necessary discount to make consumers let go of the receipts, it could also create a friction in pinning down the right discount level that may contribute to the collusion costs.

The relative effectiveness of lotteries compared to tax rebates would be a relevant comparison for a cost-benefit analysis, but the variation in the data does not allow to distinguish the two in a compelling manner. As discussed in Section I, tax rebates could also be leveraging a behavioral effect if framing an additional gain in a separate category ("rebate") is valued more than an cash equivalent discount. Evaluating the relative effectiveness of different reward systems is an interesting avenue for future research.

\section{Implications for Tax Policy}

The results in the previous sections show that incentives for consumers to ensure that firms accurately report transactions can be an effective way to improve firm compliance in final sales transactions. The implications for tax policy and its welfare consequences, however, require additional analysis. The effect on tax revenue does not necessarily have to mirror the increase in reported revenue as it depends on the extent to which expenses can be adjusted. Moreover, even if the effect of the policy on tax revenue is positive, it is crucial to evaluate such increase net of consumer rewards. There are also a number of additional costs and benefits for the government, firms, and consumers that should be considered in a welfare analysis. I begin this section by investigating the impact of the policy on tax revenue. Then, I discuss the welfare implications of different components of consumer rewards programs.

\section{A. Tax Revenue Implications}

It is possible that firms' tax liabilities do not respond to the policy in the same way as reported revenue. In fact, the response could be proportionally larger or smaller. It could be larger if, for instance, firms in the VAT do not adjust their expenses. In this 
case, the value added would increase proportionally more than the reported sales. The effect could also be smaller if expenses are adjusted to offset the increase in reported sales. ${ }^{63}$

In the context of enforcement of sales reporting in corporate income tax, Carrillo, Pomeranz, and Singhal (2017) and Slemrod et al. (2017) find that reported costs increase as well, partially offsetting the change from more accurate revenue reporting. In both cases, the cost increase occurred primarily in difficult to verify margins such as "Other expenses." In the case of the VAT, the ability to adjust inputs tax credit is arguably relatively more limited as a tax credit must be another firms' tax debit. However, VAT credit fraud is often a problem in VAT systems (Bird and Gendron 2007), and there could be under-reporting of inputs if buyers colluded with suppliers to misreport transactions (Pomeranz 2015).

In order to investigate the effect of the policy on tax revenue, I begin by looking directly at the effect of the policy on firms' tax liabilities. I focus on a subset of sectors with little tax withholding such that the total tax due reported by firms is a good measure of the total tax liability of a firm (tax sample). ${ }^{64}$ First, I run the same analysis as in Section III using the flexible DD specification (5) in the sector panel and the $\log$ of tax liabilities as an outcome. Panel A of Figure 6 shows the difference in tax liabilities between retail and wholesale sector. Similarly to reported revenue in panel B of Figure 2, there are parallel pretrends before the introduction of the policy, and a clear increase in tax liabilities in retail relatively to wholesale after the policy. The DD estimate is a statistically significant 25.9 percent increase in tax liabilities, which is close to the figure for reported revenue in Section III. ${ }^{65}$

Panel A of Table 3 shows the results using firm-level data and running the DD specification (7) for the tax sample. Column 1 shows the DD coefficient for the log of reported revenue for this subset of firms. The effect is a bit larger than in the main sample, but confidence intervals overlap. Column 2 shows the DD coefficient using the log of tax liabilities, and the results indicate a statistically significant 31.6 percent increase in reported tax liabilities. Because the liability is zero in some cases, I also use a binary outcome for positive tax liability, but I find no effect on the extensive margin.

The tax liability analysis above is limited to a subsample of sectors, so in order to shed light on the effect of the policy on total tax revenue, I look at changes in the tax revenue in São Paulo as a share of GDP compared to all other states combined (leaving São Paulo out) in panel B of Figure 6, using data from the Brazilian Central Bank. The figure shows a slight level shift in tax/GDP in São Paulo of 3.5 percent relative to the rest of the country after 2007. This increase is consistent with an effect of the policy on retail tax revenue similar to the 25.9 percent increase estimated above as taxes in retail are less than 15 percent of the total tax revenue.

\footnotetext{
${ }^{63}$ To illustrate this point let value added be $V A=Y-E$, where $Y$ is reported revenue and $E$ is reported expenses, and let $\delta^{x}=\Delta x / x$ be the change in variable $x$. $\delta^{V A}=\left(\delta^{Y} Y-\delta^{E} E\right) /(Y-E)$. If $\delta^{Y}=\delta^{E}=\bar{\delta}$, $\delta^{V A}=\bar{\delta}$. Also, if $\delta^{Y}<\delta^{E}, \delta^{V A}<\delta^{Y}$.

${ }^{64}$ The data available to this study have some measurement challenges discussed in Section IIC and online Appendix B.

${ }^{65}$ Online Appendix Figure A4 shows the results for reported revenue for the same subsample of sectors used in the tax liability results (tax sample). The point estimate is slightly larger ( 28 percent) than in the main sample, but the confidence intervals overlap.
} 
Panel A. Tax liabilities: retail versus wholesale

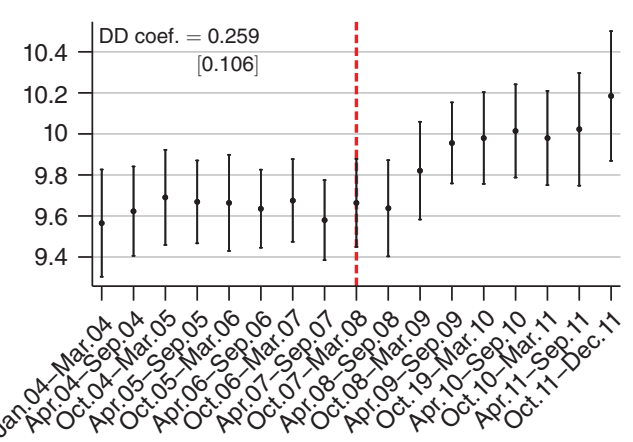

Panel B. VAT as a share of GDP

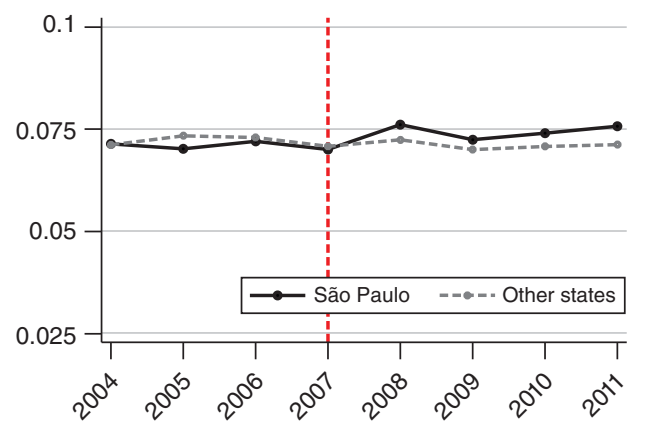

Figure 6. Effect of the Policy on Tax Revenue

Notes: Panel A plots regression coefficients from estimating specification (5) using log of tax liabilities as the dependent and a sample of sectors for which total tax due best approximates the tax liability of firms between January 2004 and December 2011 (see online Appendix B for more detail). Similarly, the difference-in-differences (DD) coefficient displayed in the figure is estimated using log of tax liabilities as the dependent variable in specification (6). The DD variable is defined by the interaction between a dummy for retail sectors and a dummy that equals 1 for time periods after October 2007. This sector sample has 5,088 observations and standard errors are clustered by sector. Online Appendix Figure A4 shows the effect of the policy on reported revenue using the same tax sample. Panel B shows total VAT revenue in São Paulo as a share of the state's GDP comparing with total VAT collected in Brazil as a share of the total GDP in Brazil using data from the Brazilian Central Bank. The figures for Brazil include all Brazilian states leaving São Paulo out. Panel B of online Appendix Table A3 shows robustness checks.

The evidence from both the sector-level analysis and the firm-level data suggest that the percentage change in tax liabilities is similar to the percentage change found in reported revenue. As discussed above, the similarity in the effect is not obvious ex ante, since it depends on how input claims can be adjusted. Given the evidence so far, any change in reported inputs is not completely offsetting the increase in reported revenue generated by the policy. ${ }^{66}$ In order to investigate reported expenses, I use data from a subset of firms that were in the VAT system throughout the period of analysis. 67

Panel B of Table 3 shows the effect of the policy for firms in this subsample using specification (7). In column 1, I show the DD coefficient on the log of reported revenue. The point estimate is also positive and statistically significant. It is again a bit larger than in the main sample but confidence intervals overlap. The DD effect on $\log$ of reported inputs in column 2 is significant and only slightly smaller than the effect on reported revenue. The effect on the value added defined by the difference between revenue and input is also significant and similar to the effect on reported revenue. Since some firms have nonpositive value added, I also look at a binary outcome for positive value added in column 4 . The effect is not statistically sig-

\footnotetext{
${ }^{66}$ For firms outside the VAT, in the turnover regime, an increase in reported revenue would lead to a proportional increase in tax liabilities. However, the majority of the tax collected in retail comes from VAT firms (over 85 percent), so the adjustment of expenses is still a relevant margin of response.

${ }^{67}$ Firms may switch in and out of the VAT over the period of analysis. When firms are in the simplified tax regime, they do not report inputs as their tax base is turnover. Therefore, it is important to restrict attention to firms that never changed tax regimes to make sure reported inputs can be measured across time. For more details, see online Appendix B.
} 
Table 3-Tax Liability and Reported Expenses: Retail versus Wholesale

\begin{tabular}{|c|c|c|c|c|}
\hline & $\begin{array}{c}\log \text { of } \\
\text { reported revenue } \\
(1)\end{array}$ & $\begin{array}{c}\log \text { of } \\
\text { tax liability } \\
(2)\end{array}$ & $\begin{array}{l}\text { Positive tax } \\
\text { liability } \\
\text { (3) }\end{array}$ & \\
\hline $\begin{array}{l}\text { Panel A. Tax sample } \\
\text { DD }(\text { post October } 07 \times \text { retail })\end{array}$ & $\begin{array}{c}0.311 \\
{[0.151]}\end{array}$ & $\begin{array}{c}0.316 \\
{[0.137]}\end{array}$ & $\begin{array}{l}0.043 \\
{[0.0350]}\end{array}$ & \\
\hline $\begin{array}{l}\text { Firm fixed effects } \\
\text { Time fixed effects }\end{array}$ & $\begin{array}{l}\mathrm{X} \\
\mathrm{X}\end{array}$ & $\begin{array}{l}X \\
X\end{array}$ & $\begin{array}{l}\mathrm{X} \\
\mathrm{X}\end{array}$ & \\
\hline \multirow[t]{2}{*}{ Adjusted $R^{2}$} & $\begin{array}{c}167,110 \\
0.85\end{array}$ & $\begin{array}{c}133,950 \\
0.876\end{array}$ & $\begin{array}{c}167,110 \\
0.801\end{array}$ & \\
\hline & $\begin{array}{c}\log \text { of } \\
\text { reported revenue } \\
(1)\end{array}$ & $\begin{array}{l}\log \text { of } \\
\text { reported inputs } \\
(2)\end{array}$ & $\begin{array}{l}\log \text { of reported } \\
\text { value added } \\
\text { (3) }\end{array}$ & $\begin{array}{c}\text { Positive } \\
\text { value added } \\
\text { (4) }\end{array}$ \\
\hline \multicolumn{5}{|c|}{ Panel B. Expenses, output and value added-firms that were always VAT } \\
\hline DD (post October $07 \times$ retail $)$ & $\begin{array}{l}0.363 \\
{[0.0824]}\end{array}$ & $\begin{array}{c}0.302 \\
{[0.0833]}\end{array}$ & $\begin{array}{c}0.387 \\
{[0.105]}\end{array}$ & $\begin{array}{l}0.019 \\
{[0.0153]}\end{array}$ \\
\hline Firm fixed effects & $\mathrm{X}$ & $\mathrm{X}$ & $\mathrm{X}$ & $\mathrm{X}$ \\
\hline Time fixed effects & $\mathrm{X}$ & $\mathrm{X}$ & $\mathrm{X}$ & $\mathrm{X}$ \\
\hline Observations & 88,422 & 88,422 & 70,845 & 88,422 \\
\hline Adjusted $R^{2}$ & 0.87 & 0.85 & 0.90 & 0.71 \\
\hline
\end{tabular}

Notes: Table 3 displays the main coefficients form regressions described in Section $\mathrm{V}$ using the firm-level data. The variable $D D$ is defined as the interaction between a dummy for retail sectors (Retail) and a dummy that equals 1 for time periods after October 2007 (Post October 07). The data are collapsed into two periods: before and after October 2007. Time and firm fixed effects are included in all regressions. The regressions are dollar-weighted (each observation is weighted by the pre-policy reported revenue) such that each observation contributes to all regression estimates according to its economic scale to best approximate the aggregate effect. Panel A reports the results for a sample of firms (Tax sample) that are in sectors where there is little tax withholding and, therefore, the firmlevel reported tax liabilities in the data best approximates their own tax liabilities (see online Appendix B for more details). Column 1 shows the DD results for the $\log$ of reported revenue as in Table 2 column 1, but for the tax sample. The outcome in column 2 is the log of tax liabilities that excludes non-positive values, and column 3 reports the effect on a binary outcome of whether firms report positive liabilities. Panel B reports the coefficients for a sample of firms from all sectors that are registered as VAT throughout the data period (January 2004 - December 2011). Column 1 shows the DD results for the log of reported revenue as in column 1 of Table 2 for this subsample. Column 2 shows the DD coefficient for the log reported inputs. The outcome in column 3 is the log of value added that excludes non-positive values, so column 4 reports the effect on a binary outcome of whether firms report positive value added. Standard errors are clustered at the sector level. See online Appendix Table A3 for robustness checks.

nificant. Hence, even though firms do adjust inputs, there is still an increase in the value added, which is in line with the findings above where percentage change in tax liabilities is similar to the percentage change in reported revenue.

The results above suggest that the increase in compliance generated an increase in the effective tax rate. In online Appendix D, I study real responses to the policy by analyzing formal employment and number of firms in the market by seven-digit sector. The evidence indicates that the increase in tax enforcement did not affect these outcomes during the period of analysis. The null effect may indicate that the implied increase in the effective tax rate is not large enough to affect firms along these margins, and may just reduce evasion rents. The lack of real responses is consistent with the increase in reported revenue being a reporting effect, rather than 
an actual increase in sales, in which case I could potentially observe an increase in employment or in the number of firms.

Tax Revenue Net of Rewards: The government of São Paulo is forgoing part of the tax revenue collected at the final consumer stage by paying the consumer rewards: both incremental revenue from the program, and infra-marginal revenue. Therefore, even if the effect of the policy is positive, it is not clear that the program is able to increase revenue net of transfers.

To perform this calculation, consider the 25.9 percent point estimate change in tax liabilities from the sector-level results. The government is rewarding consumers with 33 percent of the tax collected in final sales transactions: 30 percent in tax rebate and 3 percent in lottery prizes. Considering that these rewards will be applied to 40 percent of the transactions (as shown in Figure 1), the total revenue increase net of rewards would then be 9.3 percent. ${ }^{68}$

There are also administrative costs on the government side that should be considered, but there is no official estimate of such costs. Even if they are substantial, it is important to note that the NFP is also arguably relying on the fact that some consumers may never collect rewards. As of 2011, 50 percent of the rewards were not collected. In particular, there are 27 million consumers who asked for SSN receipts but did not enroll online in the first four years of the program, which is the only way one can claim rewards. Considering the unclaimed rewards, the total tax revenue net of rewards would have increased by 17.6 percent. This fact highlights two relevant aspects of the policy: (i) the total revenue effect net of rewards could be larger as consumers leave money on the table; (ii) there are nontrivial costs for consumers to fully participate in this policy that should be considered in the welfare implications.

\section{B. Welfare Discussion}

So far, I have focused on the effects of consumer reward policies on firms and their impact on tax revenue. The welfare implications of such policies must also consider social costs and benefits. For instance, improving enforcement could help tilt the playing field in retail away from firms that evade taxes toward the most-efficient firms. Also, it is important to consider how such policies affect the government and consumers beyond redistributive effects of transfers from firms to the government (from additional taxes), or transfers from firms to consumers (through discounts in collusive deals). ${ }^{69}$

\footnotetext{
${ }^{68}$ Consider an extreme case of 100 percent of receipts with a SSN. In this case, as discussed in the comparative statics of Section I, the government would need an increase in tax collection by almost 50 percent (i.e., $0.33 /(1-0.33))$ to break even because the reward is applied to all tax transaction at final sales. In the data, 40 percent of the receipts will receive a reward, so the minimum increase in tax collection to break even becomes 15.2 percent (i.e., $(0.33 \times 0.4) /(1-0.33 \times 0.4))$.

${ }^{69}$ On the firm side, I am abstracting from costs imposed by the program because firms are required to send receipts to the government irrespective of the NFP program. There could be additional time costs from having to enter the SSN digits in the receipts, but I am abstracting from those as there are readily available technologies that could eliminate such costs and are already being adopted in the context of consumer rewards. For instance, the NFP created consumer cards with bar codes that could be scanned to speed up the process. Another example is that the most recent receipt technology has a QR code that can be scanned by consumer rewards smart-phone applications.
} 
The data available to this study do not allow to fully investigate the welfare implications of the NFP, so the aim of this section is to highlight some key points that should be considered in the design of consumer reward policies. Countries adopted different policy bundles, with varying generosity in the reward values and technological sophistication. I discuss the costs and benefits associated with two relevant dimensions of such policies and their welfare implications: (i) information and tax morale campaigns; (ii) monetary rewards.

Information and Tax Morale Campaigns: It is possible that consumers value tax compliance and have some local information on evasion by firms, but are not fully aware of the importance of official receipts nor of how to volunteer information on tax evasion to the government. In this case, an information campaign that fosters tax morale and emphasizes the importance of issuing receipts and how consumer can whistle-blow firms could leverage a utility gain from a "warm glow" of contributing to an anti-tax evasion program. From Section I, if consumers value receipts even absent of monetary rewards $(\kappa(0)>0)$, they would ask for receipts and affect firm behavior through both mechanisms highlighted in Section IV: whistle-blower threats and collusion costs as firms would have to offer discounts to compensate consumers for the utility they would gain from getting a receipt.

To fix ideas, assume that such a program without monetary rewards is able to improve firm compliance. In this case, the cost imposed on consumers is low as asking for receipts is driven by a utility gain from the "warm glow" effect, and consumer participation is not being subsidized through rewards. For the government, there would be costs associated to running such campaigns and managing complaints from whistle-blowers. In the case of São Paulo, there are no official numbers on the IT and personnel costs to run the NFP program, but new information technologies are making it cheaper for governments to invest in such information channels beyond tax enforcement. ${ }^{70}$ Without monetary rewards to consumers, the cost-benefit of the policy would likely be positive for the government as it is harnessing a tax morale motivation of consumers to ask for receipts, and the government is gathering new information for enforcement. It is worth noting, however, that there could be social costs from this additional surveillance by potentially lowering social cohesion and trust.

Monetary Rewards: Most policies of this kind offer rewards to consumers, through tax rebates, cash lotteries, or in-kind prizes. If rewards are the main driver of the impact of such policies, it implies that there are costs (e.g., time costs) borne by the consumers that prevent them from asking for receipts, and that the rewards are working as a subsidy to increase the number of receipts requested by consumers. In this case, there could be a dead-weight loss (e.g., from changing time allocation of consumers). Further, the fact that these rewards could be leveraging a behavioral effect complicates the welfare assessment. Considering that the behavioral effect amplifies the perceived size of the subsidy $(\kappa(\alpha)>\alpha)$, the change in propensity to participate in the policy would be comparable to that of a higher reward rate. If

\footnotetext{
${ }^{70}$ For example, in Pakistan, the Punjab Citizens Feedback Monitoring Scheme allows citizens to report petty corruption and other public service delivery issues using their mobile phones (Bhatti, Kusek, and Verheijen 2014).
} 
$\kappa(\alpha)>\alpha$ from a utility gain because consumers enjoy playing the lottery, there is no additional cost to consumers. If rewards are leveraging a misperception of consumers (e.g., misperception of lottery probabilities), the effective gains would be lower than expected, so consumers could actually be worse off.

For the government, monetary rewards paid to consumers reduce the tax revenue it can obtain. Moreover, there are administrative costs associated with managing the rewards. In this case, rewards that leverage nonfinancial incentives can be particularly attractive. Taste for gambling and misperception of probabilities make lotteries a cost-effective reward. They are indeed widely used across the world in such programs.

In practice, many programs have a combination of information and tax morale campaigns and monetary rewards. There could be relevant complementarities between the two: if monetary rewards can be thought as a temporary nudge to shift social norms, the program could potentially generate a change in consumer's propensity to ask for receipts even if the government eventually discontinues or reduces the rewards. It an is open question, though, whether there are long-term impacts of such programs. In addition, there could be concerns of monetary rewards crowding out intrinsic motivations to ask for receipts. In the case of São Paulo, consumers can donate their rewards to charities, which may increase utility from altruistic motives and mitigate these concerns.

In future research, it would be important to build more evidence on the relative cost-effectiveness and welfare implications of different reward options: tax rebates, lotteries with in-kind prizes, or cash lottery prizes. The composition of rewards is relevant for the costs of the program to the government, and it is likely key for consumer take-up. A related open question is the critical mass level of consumer take-up that such programs need to obtain a sizable enforcement effect, and what is the most cost-effective way to achieve it.

\section{Conclusion}

Access to substantial third-party information trails is widely believed to be critical for modern tax enforcement. This paper has investigated how the availability of third-party information can improve firms' compliance. I exploit administrative data and quasi-experimental variation from a policy that rewards consumers for ensuring that firms accurately report final sales transactions to the government in São Paulo, Brazil.

I find that the program increased revenue reported in retail sectors by at least 21 percent over four years. I examine heterogeneity across firms and consumer responses to rewards to shed light on the mechanisms. I find that the estimated effect is stronger for smaller firms, for sectors with a high number of different consumers, high volume of transactions, and small ticket items. The findings are consistent with the argument that whistle-blower threats and collusion costs could help explain how self-enforcing incentives can be effective to harness third-party information in a context of extensive opportunities for tax evasion. I also provide direct evidence on the enforcement effect triggered by consumers blowing the whistle: firms report 7 percent more receipts and 3 percent more revenue after receiving their first complaint. 
Furthermore, I show that consumers are finely tuned to the incentives of the program, and I exploit the random component of lottery rewards to investigate the effect of lotteries on consumer engagement with the policy. I find that consumers condition their participation on past lottery wins. Even small prizes generate a significant and steady increase in the number of receipts consumers request, and the total value of receipts. The results are consistent with the possibility that lotteries amplify consumer responses due to behavioral biases, which would make it more costly for firms to try to match government incentives in order to collude with consumers.

Finally, I study the effect of the policy on tax liabilities. I find that tax revenue increased despite a significant adjustment in reported expenses. I calculate that the policy generated an increase in tax revenues of 9.3 percent net of rewards.

From a policy perspective, this study sheds light on how citizen engagement can be used as a monitoring tool in hard-to-tax sectors with numerous small taxpayers in a participatory program. In the context of VAT systems, the results indicate that incentives to consumers can potentially help address the last-mile problem of the VAT, which is a well-known shortcoming of one of the most important and prevalent tax instruments in the world.

\section{REFERENCES}

-Allingham, G. Michael, and Agnar Sandmo. 1972. "Income Tax Evasion: A Theoretical Analysis." Journal of Public Economics 1 (3-4): 323-38.

Andreoni, James, Brian Erard, and Jonathan Feinstein. 1998. "Tax Compliance." Journal of Economic Literature 36 (2): 818-60.

Arbex, Marcelo, and Enlinson Mattos. 2015. "Optimal Sales Tax Rebates and Tax Enforcement Consumers." Oxford Economic Papers 67 (2): 479-93.

Barroso, Rafael, and João Pedro Cortez. 2007. "Devolvendo impostos para arrecadar mais: uma avaliação dos efeitos da Nota Fiscal Paulista na arrecadação do ICMS no Estado de São Paulo." Unpublished.

Batra, Geeta, Daniel Kaufmann, and Andrew H. W. Stone. 2003. Investment Climate around the World: Voices of the Firms from the World Business Environment Survey. Washington, DC: World Bank.

-Bertrand, Marianne, Esther Duflo, and Sendhil Mullainathan. 2004. "How Much Should We Trust Differences-in-Differences Estimates?" Quarterly Journal of Economics 119 (1): 249-75.

Besley, Timothy, and Torsten Persson. 2013. "Taxation and Development." In Handbook of Public Economics, Vol. 5, edited by Alan J. Auerbach et al., 51-110. Amsterdam: Elsevier.

- Besley, Timothy, and Torsten Persson. 2014. "Why Do Developing Countries Tax So Little?" Journal of Economic Perspectives 28 (4): 99-120.

Best, Michael Carlos, Anne Brockmeyer, Henrik Jacobsen Kleven, Johannes Spinnewijn, and Mazhar Waseem. 2015. "Production versus Revenue Efficiency with Limited Tax Capacity: Theory and Evidence from Pakistan." Journal of Political Economy 123 (6): 1311-55.

Bhatti, Zubair K., Jody Zall Kusek, and Tony Verheijen. 2014. Logged On: Smart Government Solutions from South Asia. Washington, DC: World Bank.

Bird, Richard M. 1992. “Tax Reform in Latin America: A Review of Some Recent Experiences.” Latin American Research Review 27 (1): 7-36.

Bird, Richard M., and Pierre-Pascal Gendron. 2007. The VAT in Developing and Transitional Countries. New York: Cambridge University Press.

-Bordalo, Pedro, Nicola Gennaioli, and Andrei Shleifer. 2013. "Salience and Asset Prices." American Economic Review 103 (3): 623-28.

Bruhn, Miriam, and David McKenzie. 2014. "Entry Regulation and the Formalization of Microenterprises in Developing Countries." World Bank Research Observer 29 (2): 186-201.

- Carrillo, Paul, Dina Pomeranz, and Monica Singhal. 2017. "Dodging the Taxman: Firm Misreporting and Limits to Tax Enforcement." American Economic Journal: Applied Economics 9 (2): 144-64.

Cowell, Frank. 2004. "Carrots and Sticks in Enforcement." In The Crisis in Tax Administration, edited by Henry J. Aaron and Joel Slemrod, 230-75. Washington, DC: Brookings Institution. 
de Paula, Áureo, and Jose A. Scheinkman. 2010. "Value-Added Taxes, Chain Effects, and Informality." American Economic Journal: Macroeconomics 2 (4): 195-221.

DiNardo, John, Nicole M. Fortin, and Thomas Lemieux. 1996. "Labor Market Institutions and the Distribution of Wages, 1973-1992: A Semiparametric Approach.” Econometrica 64 (5): 1001-44.

do Amaral, Gilberto Luiz, João Eloi Olenike, Letícia Mary F. do Amaral, and Fernando Steinbruch. 2010. Carga Tributária Brasileira 2009 e Revisão Dos Períodos Anteriores. Curitiba, Brazil: Instituto Brasileiro de Planejamento Tributário.

Dyck, Alexander, Adair Morse, and Luigi Zingales. 2010. "Who Blows the Whistle on Corporate Fraud?" Journal of Finance 65 (6): 2213-53.

Eissa, Nada, Andrew Zeitlin, Saahil Karpe, and Sally Murray. 2014. Incidence and Impact of Electronic Billing Machines for VAT in Rwanda. London: International Growth Centre.

-Fabbri, Marco. 2015. "Shaping Tax Norms through Lotteries." International Review of Law and Economics 44: 8-15.

Filiz-Ozbay, Emel, Jonathan Guryan, Kyle Hyndman, Melissa Kearney, and Erkut Y. Ozbay. 2015. "Do Lottery Payments Induce Savings Behavior? Evidence from the Lab." Journal of Public Economics 126: 1-24.

Fooken, Jonas, Thomas Hemmelgarn, Benedikt Herrmann. 2015. Improving VAT Compliance-Random Awards for Tax Compliance. Luxembourg: Directorate-General Taxation and Customs Union, European Commission.

Friedman, Milton, and Leonard J. Savage. 1948. "The Utility Analysis of Choices Involving Risk." Journal of Political Economy 56 (4): 279-304.

Gordon, Roger, and Wei Li. 2009. "Tax Structures in Developing Countries: Many Puzzles and a Possible Explanation." Journal of Public Economics 93 (7-8): 855-66.

Guillén, Mauro F., and Adrian E. Tschoegl. 2002. "Banking on Gambling: Banks and Lottery-Linked Deposit Accounts." Journal of Financial Services Research 21 (3): 219-31.

Guryan, Jonathan, and Melissa S. Kearney. 2008. "Gambling at Lucky Stores: Empirical Evidence from State Lottery Sales.” American Economic Review 98 (1): 458-73.

Haddad, Eduardo A., Carlos A. Luque, Gilberto T. Lima, Sergio N. Sakurai, Silvio M. Costa, et al. 2011. "Impact Assessment of Interregional Government Transfers in Brazil: An inputoutput Approach.” Unpublished.

Hoopes, Jeffrey L., Daniel H. Reck, and Joel Slemrod. 2015. “Taxpayer Search for Information: Implications for Rational Attention.” American Economic Journal: Economic Policy 7 (3): 177-208.

International Monetary Fund. 2011. Revenue Mobilization in Developing Countries. Washington, DC: Fiscal Affairs Department.

Jensen, Anders. 2019. "Employment Structure and the Rise of the Modern Tax System.” NBER Working Paper 25502.

Kaustia, Markku, and Samuli Knüpfer. 2008. "Do Investors Overweight Personal Experience? Evidence from IPO Subscriptions.” Journal of Finance 63 (6): 2679-2702.

Kearney, Melissa Schettini, Peter Tufano, Jonathan Guryan, and Erik Hurst. 2010. "Making Savers Winners: An Overview of Prize-Linked Savings Products.” NBER Working Paper 16433.

Keen, Michael, and Ben Lockwood. 2010. "The Value Added Tax: Its Causes and Consequences.” Journal of Development Economics 92 (2): 138-51.

Keen, Michael, and Jack Mintz. 2004. "The Optimal Threshold for a Value-Added Tax." Journal of Public Economics 88 (3-4): 559-76.

Kleven, Henrik Jacobsen. 2014. "How Can Scandinavians Tax So Much?” Journal of Economic Perspectives 28 (4): 77-98.

Kleven, Henrik Jacobsen, Martin B. Knudsen, Claus Thustrup Kreiner, Søren Pedersen, and Emmanuel Saez. 2011. "Unwilling or Unable to Cheat? Evidence from a Tax Audit Experiment in Denmark." Econometrica 79 (3): 651-92.

Kleven, Henrik Jacobsen, Claus Thustrup Kreiner, and Emmanuel Saez. 2016. "Why Can Modern Governments Tax So Much? An Agency Model of Firms as Fiscal Intermediaries." Economica 83 (330): 219-46.

Kopczuk, Wojciech, and Joel Slemrod. 2006. "Putting Firms into Optimal Tax Theory." American Economic Review 96 (2): 130-34.

Kumler, Todd, Eric Verhoogen, and Judith Frias. 2012. "Enlisting Workers in Monitoring Firms: Payroll Tax Compliance in Mexico.” Columbia University Department of Economics Discussion Paper 96.

La Porta, Rafael, and Andrei Shleifer. 2014. "Informality and Development." Journal of Economic Perspectives 28 (3): 109-26.

Marchese, Carla. 2009. "Rewarding the Consumer for Curbing the Evasion of Commodity Taxes?" FinanzArchiv: Public Finance Analysis 65 (4): 383-402. 
Mattos, Enlinson, Fabiana Rocha, and Patrícia Toporcov. 2013. "Programas de incentivos fiscais são eficazes? Evidência a partir da avaliação do impacto do programa nota fiscal paulista sobre a arrecadação de ICMS.” Revista Brasileira de Economia 67 (1): 97-120.

Monteiro, Joana C. M., and Juliano J. Assunção. 2012. "Coming Out of the Shadows? Estimating the Impact of Bureaucracy Simplification and Tax Cut on Formality in Brazilian Microenterprises." Journal of Development Economics 99 (1): 105-15.

Musgrave, Richard Abel. 1969. Fiscal Systems. New Haven, CT: Yale University Press.

Naritomi, Joana. 2019. "Consumers as Tax Auditors: Dataset." American Economic Review. https:// doi.org/10.1257/aer.20160658.

Pomeranz, Dina. 2015. "No Taxation without Information: Deterrence and Self-Enforcement in the Value Added Tax." American Economic Review 105 (8): 2539-69.

-Shleifer, Andrei, and Robert W. Vishny. 1993. "Corruption.” Quarterly Journal of Economics 108 (3): 599-617.

Slemrod, Joel. 2007. "Cheating Ourselves: The Economics of Tax Evasion.” Journal of Economic Perspectives 21 (1): 25-48.

-Slemrod, Joel, Brett Collins, Jeffrey L. Hoopes, Daniel Reck, and Michael Sebastiani. 2017. "Does Credit-Card Information Reporting Improve Small-Business Tax Compliance?” Journal of Public Economics 149: 1-19.

Slemrod, Joel, and Christian Gillitzer. 2013. Tax Systems. Cambridge, MA: MIT Press.

Slemrod, Joel, and Shlomo Yitzhaki. 2002. "Tax Avoidance, Evasion, and Administration.” In Handbook of Public Economics, Vol. 3, edited by Alan J. Auerbach and Martin Feldstein, 1423-70. Amsterdam: Elsevier.

-Stephens-Davidowitz, Seth. 2014. "The Cost of Racial Animus on a Black Candidate: Evidence Using Google Search Data." Journal of Public Economics 118: 26-40.

Thaler, Richard H. 1999. "Mental Accounting Matters." Journal of Behavioral Decision Making 12 (3): 183-206.

Tirole, Jean. 1986. "Hierarchies and Bureaucracies: On the Role of Collusion in Organizations." Journal of Law, Economics, and Organization 2 (2): 181-214.

Tufano, Peter. 2008. "Saving whilst Gambling: An Empirical Analysis of UK Premium Bonds." American Economic Review 98 (2): 321-26.

-Wan, Junmin. 2010. "The Incentive to Declare Taxes and Tax Revenue: The Lottery Receipt Experiment in China." Review of Development Economics 14 (3): 611-24.

-Yagan, Danny. 2015. "Capital Tax Reform and the Real Economy: The Effects of the 2003 Dividend Tax Cut.” American Economic Review 105 (12): 3531-63.

Yaniv, Gideon. 1993. Collaborated Employee-Employer Tax Evasion. The Hague: National Insurance Institute, Administration of Research and Planning. 